\title{
Evaluar el reajuste de tierras en Colombia: la distribución equitativa entre actores*
}

Fecha de recepción: 17 de febrero de 2016 | Fecha de aprobación: 27 de julio de 2018 । Fecha de publicación: 22 de abril de 2019

Ricardo Andrés Daza Hoyos

Architecture for Humanity Bogotá,

Colombia

Resumen El reajuste de tierras o integración inmobiliaria (LR, por su nombre en inglés) ${ }^{1}$ existente en Colombia desde 1997 ha presentado dificultades en su proceso de implementación, las cuales no garantizan la equidad. Este artículo examina la capacidad de los actores para compartir el incremento del valor de la tierra en los planes parciales desarrollados con esta herramienta en Colombia. Se concluye que existe una diferencia significativa entre las cargas y los beneficios de cada grupo de actores. La evidencia indica que los proyectos de reajuste de tierras en Colombia difieren de su definición teórica y contradicen sus características fundamentales: el método de englobe, al desplazar los propietarios originales de las tierras y la distribución equitativa, por el liderazgo de los privados, que reciben más beneficios de los que deben.

actores, Colombia, equidad, reajuste, tierras

El término land readjustment se traduce del inglés como reajuste de tierras. En el contexto colombiano se ha diferenciado por tipologías y maneras de implementarlo: el reajuste de tierras en contextos de incorporación de suelo rural para convertirlo en suelo urbano y la integración inmobiliaria en contextos de redesarrollo de predios urbanos. También existe una forma básica de land readjustement llamada cooperación entre partícipes, que no conIleva al englobe de terrenos (Maldonado, Pinilla, Rodríguez y Valencia, 2006). Para esta investigación se utiliza el término reajuste de tierras como el más genérico y se entienden los demás como diferentes manifestaciones de la misma metodología 0, como lo referencia Hong (2007), diferentes etapas en la evolución de la herramienta. 


\section{Evaluating the Land Readjustment in Colombia:}

An Equitable Distribution among the Actors

\section{Abstract Abstract}

Land Readjustment ${ }^{2}$ (LR) or real estate assembling carried out in Colombia since 1997 has had some difficulties in the implementation process, which has not ensured the expected equity. This article examines the involved actor's abilities to share the land appreciation due to the partial plans developed with this tool in Colombia. It is concluded that there is a significant difference between burdens and benefits in each actor group. Evidence indicates that the LR projects in Colombia differ from the theoretical definition and go against its essential characteristics: the merging method that displaces the original landowners and affects the equitable distribution and promotes the leadership of private companies that get more benefits than they should.

Keywords actors, Colombia, equity, readjustment, land

\section{Avaliar o reajustamento de terras na Colômbia:} a distribuição equitativa entre atores

Resumo O reajustamento de terras ou integração imobiliária (LR, pelo nome em inglês) ${ }^{3}$ existente na Colômbia desde 1997 já apresentou dificuldades no seu processo de implementação, o que náo garante equidade. Este artigo examina a capacidade dos atores para compartilhar o acréscimo do valor da terra em planos parciais desenvolvidos com esta ferramenta na Colômbia. Conclui-se que há uma diferença significativa entre as cargas e benefícios de cada grupo de atores. As evidências indicam que os projetos de reajuste de terras na Colômbia diferem da sua definição teórica e contradizem suas características fundamentais: o método de englobamento, ao deslocar os possuidores originais das terras e a distribuição equitativa, pela liderança dos privados, que recebem mais benefícios dos devidos.

Palavras chave atores, Colômbia, equidade, reajuste, terras

\footnotetext{
2 Land Readjustment has been translated into Spanish as "reajuste de tierras". In the Colombian context it has been broken down according to typologies and the different ways of implementing it: Land Readjustment in contexts of transforming rural lands into urban lands and the merging of real estate in contexts of urban lot redevelopment. There is also a basic form of Land Readjustment known as Cooperation between parties, which does imply a land merging (Maldonado et al., 2006). This research uses the term Land Readjustment as the most generic, while the others are understood as different expressions of a same methodology or, as stated by Hong (2007), different stages of the tool evolution.

30 termo land readjustmenté traduzido do inglês como reajuste de terras. No contexto colombiano tem se diferenciado por tipologias e maneiras de implementá-lo: 0 reajuste de terras em contextos de incorporação de solo rural para convertê-lo em solo urbano e a integração imobiliária em contextos de redesenvolvimento de prédios urbanos. Mesmo há uma forma básica de land readjustement chamada de cooperação entre partícipes, que não implica 0 englobe de terrenos (Maldonado et al., 2006). Para esta pesquisa é utilizado o termo reajuste de terras como o mais genêrico e entendem-se os demais como diferentes manifestações da mesma metodologia o, como referenciado por Hong (2007), diferentes estágios na evolução da ferramenta.
} 


\section{Introducción}

Más de 180 planes parciales han sido decretados desde que la Ley 388 de 1997 instituyó el concepto de reajuste de tierras (Colombia, Congreso de la República, 1997). Estos planes son el marco de implementación de los principios fundamentales del concepto, es decir, la posibilidad de recuperar los costos del desarrollo del proyecto, la participación voluntaria de los propietarios y la distribución equitativa de los costos y los beneficios (Rojas y Rave, 2013). Es importante examinar esos proyectos y contrastarlos con el marco teórico del reajuste de tierras, para tener una visión general del proceso de implementación de la herramienta en el contexto colombiano y así tener la posibilidad de analizar si están siendo efectuados de acuerdo con esta metodología, casi veinte años después de su introducción.

El enfoque adoptado se basa en el reajuste de tierras de los planes parciales. Otros investigadores han estudiado el contexto de los planes parciales (Borrero, 2007; Maldonado, Pinilla, Rodríguez y Valencia, 2006), su historia y casos específicos (Pinilla, 2018; Rojas y Rave, 2013), sin examinar en detalle sus principios. Se revisaron más de treinta planes parciales en diferentes municipios de Colombia, pero solo se incluyeron aquellos que implementaban alguna forma de reajuste de tierras, es decir, varios fueron descartados porque no cumplían con los requerimientos de la investigación.

Este artículo examina los principios fundamentales de LR. Primero presenta el contexto nacional; luego, tras una revisión de la teoría sobre el tema, analiza los conceptos fundamentales y plantea la hipótesis; más adelante se presenta la metodología utilizada y, por último, los resultados de la investigación y las conclusiones, con recomendaciones sobre cómo beneficiarse de los principios fundamentales del reajuste de tierras para funcionarios municipales, propietarios y ciudadanos.

\section{Contexto nacional del reajuste de tierras}

De acuerdo con el censo de 2005, Colombia tenía 42.888.594 habitantes; 74,3\% de ellos vivía en áreas urbanas. El Departamento Administrativo Nacional de Estadística (2010) estimó que para 2015 se llegaría a los 48.034.562 de habitantes. La población urbana se ha incrementado de $31 \%$ en 1938 a $57 \%$ en 1951 y cerca de $70 \%$ en 1990 , con un crecimiento de 3,1\% aproximadamente entre 1993 y 2005. Este cambio en la población urbana muestra que en Colombia la mayoría de sus habitantes ha vivido en áreas urbanas desde la década de 1950; el mayor crecimiento poblacional causado por migraciones desde áreas rurales hacia las ciudades ya ha sucedido, a diferencia de otros países en los que continúan las grandes migraciones hacia las ciudades.

En años recientes, tres actos legislativos han cambiado el panorama de la política pública del país respecto al entorno urbano: primero, la Ley 9 de 1989 (Colombia, Congreso de la República, 1989) que reconoció la importancia del factor urbano en el desarrollo del país; segundo, la nueva Constitución de 1991, que introdujo el principio 
de solidaridad y el concepto de conjunto de derechos, que enmarca, valga la redundancia, los derechos y las responsabilidades de los propietarios, con una concepción más profunda del principio de la función social de la propiedad; la Ley 388 de 1997, también conocida como Ley de desarrollo territorial, que introdujo otros dos principios: la función pública del urbanismo y la distribución equitativa de cargas y beneficios (Colombia, Congreso de la República, 1997). Estos, junto con los principios incluidos por la Constitución de 1991, establecieron la base para que el reajuste de tierras pudiera ser implementado en Colombia.

Tradicionalmente, las ciudades colombianas han ido avanzando lote a lote. Los desarrolladores en Colombia han usado complejos procesos a largo plazo para adquirir tierra y así poder obtener propiedades adyacentes (Alfonso, 2003). Como lo muestra Rodríguez (2012), más de $50 \%$ de los planes parciales han sido desarrollados por iniciativa privada en Bogotá y Medellín y las decisiones públicas suman entre un 16 y un $23 \%$. Ya que el Gobierno no es un actor decisivo en esos procesos, no tiene medios efectivos para asegurar la inclusión de usos improductivos, porque deja la herramienta en manos del privado que, en busca de mayores ganancias, puede generar procesos de gentrificación y exclusión de los habitantes con ingresos más bajos.

Cuando el sector público ha participado en planes parciales (PP), ha expropiado o comprado terrenos para desarrollar los proyectos, mientras en el sector privado solo algunos proyectos han contado con la participación voluntaria de los propietarios. Esto desafía una condición fundamental del reajuste de tierras: la participación voluntaria de los propietarios (Hong, 2007); más aún, cuestiona la forma como los terrenos urbanos son gestionados en Colombia, ya que la tierra es uno de los aspectos fundamentales que ha tenido al país en un estado de guerra interna por más de cincuenta años. Por tal razón, es fundamental analizar si las técnicas de intimidación que se usaban en la tenencia de las tierras rurales están siendo replicadas en el contexto urbano, como se observa en el caso de la comuna 13 en Medellín ${ }^{4}$ (Centro de Memoria Histórica, 2012) y, por lo tanto, se coacciona a los propietarios que participan en los procesos de englobe de tierras.

El reajuste de tierras fue introducido en Colombia por la Ley 388 de 1997, desde la perspectiva del sistema de planeamiento espańol, como una herramienta dentro de un sistema multiescalar de planeamiento (Colombia, Congreso de la República, 1997). La primera escala está compuesta por los planes de ordenamiento territorial, establecidos como programas estatutarios para toda la ciudad. En una escala intermedia, los planes parciales (PP) y las unidades de actuación urbanística (UAU), instituidos como elementos para el planeamiento de piezas urbanas completas o grandes proyectos urbanos (Lungo, 2004), son el marco jurídico por el cual se puede implementar esta herramienta como una opción para el englobe de predios; las otras opciones contempladas incluyen la cooperación entre partícipes y la adquisición de inmuebles. Este marco jurídico multiescalar la condiciona, ya que mientras la mayoría de los reajustes se hacen dentro de planes parciales o unidades de actuación urbanística, para adoptar un plan parcial no es necesario utilizar el LR, puesto que hay otras opciones.

Se puede concluir que el reajuste de tierras en el escenario colombiano fue introducido estatutariamente como una herramienta para desarrollar los principios de la distribución equitativa de cargas y beneficios, la función pública del urbanismo y el principio de solidaridad, todo en un contexto poblacional que, desde mediados del siglo XX, ya era mayoritariamente urbano y cuyas ciudades se han extendido en un proceso predio a predio que no beneficiaba la sostenibilidad, en el

4 La pelea por el control del territorio entre las guerrillas y los grupos paramilitares en la "Comuna 13", un sector de Medellín, desplazó 3503 habitantes al interior de la ciudad entre diferentes barrios desde 1980 hasta 2009, algunos de ellos ya habían perdido su tierra en el campo siendo desplazados a la periferia urbana. Como lo explica el texto, muchas de las técnicas de intimidación usadas en los entornos rurales también fueron implementadas para forzar a los ciudadanos que vivían en la "Comuna 13" a dejar sus hogares. 
que las presiones políticas sobre la propiedad del terreno determinaron que el reajuste de tierras fuera tan solo una opción para el desarrollo de planes parciales y no una estrategia primordial.

\section{Reajuste de tierras o land readjustment}

El reajuste de tierras es una herramienta de gestión del territorio para promover la participación voluntaria de los propietarios al englobar terrenos (Hong, 2007), desarrollar proyectos compartiendo el incremento en el valor de la tierra de una manera equitativa (Hong y Cheng, 2014) y recuperar los costos de construir la infraestructura y los servicios necesarios (Doebele, 1982a).

La principal diferencia entre esta y otras metodologías de englobe de suelo es la participación voluntaria de los propietarios sin que vendan su propiedad. Este es el único factor que ninguna otra herramienta tiene (Hong, 2007; Grimes Jr., 1982; Alterman, 2007; Hong y Brain, 2012). El concepto básico establece que cualquier reajuste de tierras debe incluir a los propietarios porque, al no existir transferencia de las propiedades, se reduce el costo de transferencia del englobe. Según lo expuesto por Hong (2007), el englobe de terrenos es un gran obstáculo para el desarrollo urbano, en especial en zonas de redesarrollo donde hay una alta concentración de propietarios en un territorio muy fragmentado. Por esto, es considerado como una estrategia para reducir los costos de transacción utilizando la participación voluntaria de los propietarios. Otras formas de resolver este conflicto son la expropiación (Alterman, 2007) y los bancos de tierras (Smolka, 2013a). Sin embargo, en algunos casos, la participación voluntaria no ha sido aplicada; en otros se regula una cantidad mínima de propietarios requerida para iniciar un proceso de reajuste de tierras. Aun así, existen casos como el de Bután
(Norbu, 2018), donde los proyectos requieren el consentimiento de todos los propietarios; esto es posible gracias al esfuerzo de los funcionarios que trabajaron con la comunidad para explicar los esquemas y convencerlos de unirse a ellos.

Existe la preocupación acerca de que la participación implique altos costos de negociación porque los actores no han trabajado juntos previamente, de manera que no han tenido la experiencia de colaborar hacia el mismo objetivo (Doebele, 1982b). Por esto se dice que el reajuste de tierras solo funciona si existe una comunidad bien organizada, con experiencias previas de trabajo conjunto; en la mayoría de los casos aquí citados no existía este hábito. Como lo explica Sorensen (2007), existen otros factores que influencian la cooperación, como la necesidad de reconstruir después de un desastre o la cantidad y el grado educativo de los propietarios (Maldonado et al., 2006); sin embargo, como lo demuestra el caso de Thimphu (Norbu, 2018), lograr un consenso de los propietarios es posible si se tiene un equipo de negociadores comprometido. Por eso, los promotores neutrales tienen un rol fundamental; organizaciones sin ánimo de lucro, instituciones académicas o agencias multilaterales han desempeñado este papel en Angola, Chile, India, Bangkok y otros casos estudiados (Balakrishnan, 2018). Estas organizaciones han involucrado a los actores en un proceso continuo de participación, en el que el flujo de la información ha generado cierto grado de confianza entre ellos, previene que algún actor se vea más beneficiado que otros y promueve políticas de equidad social con la inclusión de viviendas.

Otra característica clave es su capacidad para recuperar costos de implementación. Esta particularidad es muy interesante para todos los actores, ya que hace los proyectos viables y evita cargas financieras. Como lo explica Turk (2008), la autofinanciación es muy atractiva para las 
municipios que tienen una baja capacidad financiera, para los desarrolladores que pueden tener un retorno positivo de su inversión y para los propietarios que van a incrementar el valor de sus propiedades por el esfuerzo colectivo. La forma como funciona la recuperación de costos consiste en que parte de la tierra que queda después de habilitar los servicios y la infraestructura se vende a precio de mercado para cubrir sus costos de construcción (Rojas y Rave, 2013). Esto es posible porque captura el incremento del valor de la tierra creado por las acciones de la comunidad o las del Gobierno, como lo muestran el caso de Bangkok y el de Etiopía (Leeruttanawisut y Rabé, 2018; Zeluel y Hong, 2014).

La herramienta para recuperar los costos puede ser afectada positiva o negativamente según factores como la disponibilidad de información precisa o la renuencia de los propietarios. Por otra parte, también existen criterios externos como el comportamiento del mercado inmobiliario o las regulaciones impuestas a los proyectos, por ejemplo, incluir usos no rentables. Lo que debe estar claro es que el reajuste de tierras tiene la capacidad de recuperar los costos porque moviliza el valor del suelo. Su éxito está determinado por la relación entre el incremento calculado del valor de la tierra y la magnitud de los costos que deben ser incluidos en el proyecto (Maldonado et al., 2006). Si el resultado es positivo, el excedente será compartido por los actores participantes; si la carga de los costos es mayor por factores internos, las pérdidas deben ser asumidas por todos equitativamente. Sin embargo, si las pérdidas ese deben a situaciones externas, el proyecto va a requerir de subsidios del Gobierno (Needham, 2007).

De todas las características expuestas por Turk (2008) se ha probado que algunas no son fundamentales para hacer proyectos con reajuste de tierras, como el marco jurídico (Hong, 2007) o una estructura de tenencia de tierra definida
(Payne, 2002). A pesar de que no son necesarias, esas características pueden promover proyectos más eficientes. Otros rasgos como la participación voluntaria de propietarios y la capacidad de recuperar los costos diferencian el LR de cualquier otro método de englobe y son fundamentales en su implementación.

\section{Compartir el valor de la tierra}

Existen factores diferentes a los macroeconómicos que influencian el valor de la tierra (Smolka, 2013b). Esos elementos están relacionados con el proceso de urbanización de las ciudades, terrenos rurales que son convertidos a urbanos, la construcción de redes de servicios públicos por parte del Gobierno y el cambio en los derechos de construcción o de regulaciones de uso. Todas esas acciones tienen un efecto drástico en el valor de la tierra (Borrero, 2007). Esos beneficios "windfalls" son siempre capitalizados por los propietarios si no existe una regulación apropiada para controlarlo (Hagman y Misczynski, 1977). Esos propietarios, contrario a la teoría de John Locke, no están haciendo algún trabajo o inversión en sus tierras que les otorgue derecho a reclamar esos beneficios (Alterman, 2012).

Este incremento en el valor de la tierra tiene el potencial de beneficiar a aquellos que lo crearon y no solo a los propietarios de la tierra. Académicos y organizaciones se han referido a este concepto como "capturar", "compartir" o movilizar" el valor de la tierra (Smolka, 2013b; Smolka e Iracheta, 2000; Smolka y Amborski, 2000). Esta idea está basada en el concepto de equidad, ya que la "captura de plusvalías" reconoce que hay una parte del incremento en el valor de la tierra que es creado por el esfuerzo de los propietarios y debe ser capitalizada por ellos, mientras el valor creado por el Gobierno y la sociedad debe ser para beneficiar a la ciudadanía en la misma proporción en la que cada uno haya contribuido. 
Este es también un sistema sostenible de financiar la ciudad, ya que la nueva infraestructura será construida con el incremento en el valor de la tierra.

Doebele (2007) categoriza el reajuste de tierras como la mejor herramienta para capitalizar ese incremento, porque lo captura en el momento del cambio rural-urbano y elimina la ardua labor de cobrarlo antes o después, como lo propone el impuesto único de Henry George y otras herramientas.

El concepto de "compartir el valor de la tierra" (land value sharing, en inglés) fue propuesto por el director ejecutivo de ONU-Habitat, Joan Clos (Hong y Cheng, 2014). Reconoce que el incremento en el valor de la tierra no es creado solo por las acciones de los propietarios o su valor inherente, sino también por las acciones de otros. Por eso, aquellos que lo provocaron tienen el derecho de recibir los beneficios, compartidos entre todos los actores. Ha sido promovido por la Global Land Tool Network GLTN y ONU-Habitat como parte de una nueva perspectiva del reajuste de tierras llamada "Pilar" (reajuste de tierras inclusivo y participativo) (Hong y Tierney, 2014).

"Compartir el valor de la tierra" es un sinónimo de la captura de plusvalías. Esta nueva noción busca reflejar su capacidad para crear inclusión y participación, al compartir las cargas y los beneficios entre todos los actores.

\section{Conceptos de la investigación}

Después del análisis teórico, uno de los aspectos resaltados fue el enfoque en el marco institucional. Aunque existen problemas en el proceso de implementación relacionados con el rol institucional de los Gobiernos locales, esto es una realidad para cualquier otra herramienta o proyecto. Es importante evaluar esos elementos que disminuyen la capacidad del Estado; sin embargo, como son condiciones generales que están embebidas en el contexto, no afectan la configuración inicial de la estrategia, sino su fase de implementación, por lo que esta investigación se enfoca en los otros tres criterios mencionados: la posibilidad de coerción a los propietarios para participar en el englobe de tierras, la baja capacidad de financiar usos no rentables y la distribución equitativa de los beneficios entre todos los actores.

Esos tres conceptos fueron definidos con base en los estudios desarrollados por diferentes autores. Primero, el concepto de "participación voluntaria de propietarios" es soportado por las definiciones de Doebele (1982a), Hong (2007), Turk (2008), Hong y Tierney (2014) y Hong y Cheng (2014), presentados en la tabla 1.

Tabla 1. Definición del concepto "participación voluntaria de propietarios"

\begin{tabular}{|l|l|}
\hline \multicolumn{1}{|c|}{ Fuente } & \multicolumn{1}{|c|}{ "Participación voluntaria de propietarios" } \\
\hline Doebele (1982a) & $\begin{array}{l}\text { "Land Readjustment is simply a method by which the city government, other designated public bodies, } \\
\text { or even private associations can participate directly in the process of urbanization and thereby share its } \\
\text { profits" (p. 2). }\end{array}$ \\
\hline Hong (2007) & $\begin{array}{l}\text { "Unlike in voluntary exchange or eminent domain, organizers of a land readjustment project reach out } \\
\text { to the public at the very beginning of the project to engender broad political and community support. No } \\
\text { shield companies are buying properties in the neighbourhood No condemnation notices are issued to } \\
\text { residents" (p. 14). }\end{array}$ \\
\hline Turk (2008) & $\begin{array}{l}\text { "Adoption and participation of landowners in the project will increase the applicability of LR [...] the } \\
\text { provision of a high level of support and participation by landowners is considered a fundamental point in } \\
\text { managing the projects (Sorensen 2000a, 62, 63, 65)" (p. 241). }\end{array}$ \\
\hline
\end{tabular}




\begin{tabular}{|l|l|}
\hline \multicolumn{1}{|c|}{ Fuente } & \multicolumn{1}{c}{ "Participación voluntaria de propietarios" } \\
\hline Hong y Tierney (2014) & $\begin{array}{l}\text { "It is through LR that organizers can develop a participatory planning system, democratic decision-making } \\
\text { processes, and community inclusiveness to make the proposed land swaps viable" (p. 2). }\end{array}$ \\
\hline "PlLaR also stresses the importance of an open and inclusive participation of landowners and occupants in \\
all decision-making processes" (p. 5).
\end{tabular}

Fuente: elaboración propia

Dado que el principio fundamental del reajuste de tierras plantea que es la participación voluntaria de los propietarios originales de la tierra (Doebele, 1982a) la que permite reducir los costos del proyecto y financiar la infraestructura, es fundamental definir si en Colombia los participantes del reajuste son los propietarios originales o son otros actores que se han beneficiado al comprar tierras por medio de compañías fachada (Hong, 2007) u otros métodos, lo que reduce la efectividad de la herramienta (Turk, 2008) y dificulta su implementación (Hong y Tierney, 2014).

Segundo, el concepto de la herramienta para recobrar los costos, definido con base en Doebele (1982a), Hong (2007), Turk (2008) y Hong y Tierney (2014), se muestra en la tabla 2. Esta noción es fundamental porque en Colombia, el argumento de los desarrolladores para no financiar esos costos - común en otros países- es que cubrirlos incrementa el valor de compra de los productos inmobiliarios. La herramienta de recuperación de costos, que es un factor fundamental del reajuste de tierras (Hong y Tierney, 2014), demuestra que no existe un incremento en los precios de venta; lo que sucede es un intercambio entre el valor de la tierra antes y después del reajuste (Hong, 2007) que reduce las ganancias de los desarrolladores, pero aumenta los beneficios de los propietarios, como lo describen Turk (2008) y Maldonado y otros autores (2006) respecto al caso colombiano.

Por último, el concepto de compartir el valor de la tierra, como lo definen Smolka (2013b), Alterman (2012) y Hong y Cheng (2014) visualizado en la tabla 3. Determina la posibilidad de movilizar las plusvalías generadas (Smolka, 2013b) para beneficiar a la comunidad y proporcionalmente a los actores que intervienen en el proyecto, de conformidad con el valor contribuido inicialmente (Hong y Cheng, 2014).

En Colombia es importante determinar si ese mayor valor, que ha sido producido por el cambio en el reglamento de usos del suelo (Alterman, 2012), está siendo capturado también por el público en las proporciones definidas por la Ley 388 de 1997 y sus decretos reglamentarios (Colombia, Congreso de la República, 1997). Los conceptos de la investigación, soportados en los documentos de estos autores, crean un marco teórico sólido, que pone a prueba si la interacción de los actores permitió una mejor distribución del valor de la tierra entre ellos y la sociedad. 
Tabla 2. Definición del concepto "herramienta de recuperación de costos"

\begin{tabular}{|c|c|}
\hline Fuente & "Herramienta de recuperación de costos" \\
\hline Doebele (1982) & $\begin{array}{l}\text { "A similar calculation is then made of both the costs of installing the necessary infrastructure and of the } \\
\text { probable total value of all lots when placed (with services) on the market. Comparison of these two figures } \\
\text { produces the cost-equivalent rate, [...]" (p. 2). }\end{array}$ \\
\hline Hong (2007) & $\begin{array}{l}\text { "Land readjustment projects can be self-financing only if the responsible agency can resolve the inherent } \\
\text { tradeoff between encouraging property owners' participation by reducing their land contributions to the } \\
\text { project and recovering the full costs of local infrastructure by reserving more land for public uses and sale" } \\
\text { (p. 23). }\end{array}$ \\
\hline Turk (2008) & $\begin{array}{l}\text { "Land deduction is used for the acquisition of public service areas in the project area. In some countries' } \\
\text { laws, the land defined as 'cost-equivalent land' and allocated to be sold for the purpose of covering } \\
\text { management and construction costs is included in the amount of reduction" (p. 235). }\end{array}$ \\
\hline Hong y Tierney (2014) & $\begin{array}{l}\text { "A key factor of PILaR is the possibility of raising funds to cover a portion of the infrastructure development } \\
\text { costs" (p. 28). }\end{array}$ \\
\hline \multicolumn{2}{|c|}{$\begin{array}{l}\text { "Recuperación de costos", como lo define esta investigación, es el proceso de autofinanciamiento de un reajuste de tierras al avaluar los } \\
\text { predios iniciales y calcular su valor futuro luego de la ejecución del proyecto. La diferencia debe ser reservada para ubicar servicios e } \\
\text { infraestructura necesaria para el proyecto, vender parte de la tierra para pagar su instalación y retornar a los propietarios la tierra restante } \\
\text { que ha aumentado su valor en la misma proporción en la que contribuyeron. }\end{array}$} \\
\hline
\end{tabular}

Fuente: elaboración propia

Tabla 3. Definición del concepto "compartir el valor de la tierra"

\begin{tabular}{|l|l|}
\hline \multicolumn{1}{|c|}{ Fuente } & \multicolumn{1}{c|}{ "Compartir el valor de la tierra" } \\
\hline Smolka, 2013b & $\begin{array}{l}\text { "The notion of value capture is to mobilize for the benefit of the community at large some or all of the land } \\
\text { value increments (unearned income or plusvalías) generated by actions other than the landowner's, such as } \\
\text { public investments in infrastructure or administrative changes in land use norms and regulations" (p. 2). }\end{array}$ \\
\hline Hong y Cheng, 2014 & $\begin{array}{l}\text { "[...] land value is determined not only by its intrinsic value and private investment but also by public } \\
\text { infrastructure development, regulatory changes, community actions, and general population and economic } \\
\text { growth. In sharing land value, the value related to the original productivity or location of the land paid for } \\
\text { by the owner and the increment generated by private land investment should remain in private hands. In } \\
\text { contrast, public and private developers of infrastructure may obtain the land value increment created by } \\
\text { their investments to defray a portion of the construction costs. In addition the government, acting as a } \\
\text { representative of the public, may retain a portion of the increased land value due to regulatory changes and } \\
\text { population and economic growth (Hong and Brubaker 2010, Ingram and Hong 2012)" (p. 1). }\end{array}$ \\
\hline Alterman, 2012 & $\begin{array}{l}\text { "The same generator propels indirect and direct value capture - the increase in land values due to land } \\
\text { use decisions" (p. 19). }\end{array}$ \\
\hline En el contexto de esta investigación, "compartir el valor de la tierra" se define así: movilizar el incremento en el valor de la tierra creado por \\
Ios actores, para beneficiar a la comunidad en su totalidad y a los actores en una distribución equitativa de los costos y los beneficios.
\end{tabular}




\section{Hipótesis}

La teoría de reajustes de tierras ha mostrado que las dos características constantes son la participación de los propietarios y la capacidad de recuperar los costos. Otros elementos varían de acuerdo con otros factores y pueden o no formar parte de proyectos específicos de este tipo.

Por un lado, la participación directa o indirecta de los propietarios es una constante. Existen otros actores que también han obtenido participación: el Gobierno local, cuando adquiere tierras (en una participación directa) o al otorgar permisos (en una indirecta); la comunidad de ocupantes o arrendatarios; los desarrolladores; entidades mediadoras y otros. Todos ellos se unen voluntariamente.

Por otro lado, las maneras y los formatos en los que los proyectos de reajuste de tierras (LR) han capitalizado el incremento del valor de la tierra para cubrir parcial o totalmente los costos del desarrollo de los proyectos, incluidos o no los de infraestructura y servicios, generan excedentes distribuidos de manera equitativa para todos los actores. Es también una característica fundamental que lo distancia de cualquier otra técnica de englobe de terrenos.

La hipótesis que esta investigación pone a prueba es: estas condiciones básicas son aplicadas en los proyectos con reajuste de tierras en Colombia como fueron definidas aquí por varios autores, dentro de los decretos que formalizaron cada uno de los proyectos (figura 1). Dicho de otra manera, dada la interacción entre los actores como variable independiente para esta investigación, probar si el LR en Colombia se desarrolla como lo indica la teoría, es decir, con la inclusión voluntaria de los propietarios y con los costos y los beneficios compartidos de una manera equitativa. Se entiende la distribución equitativa de los beneficios como la variable dependiente.

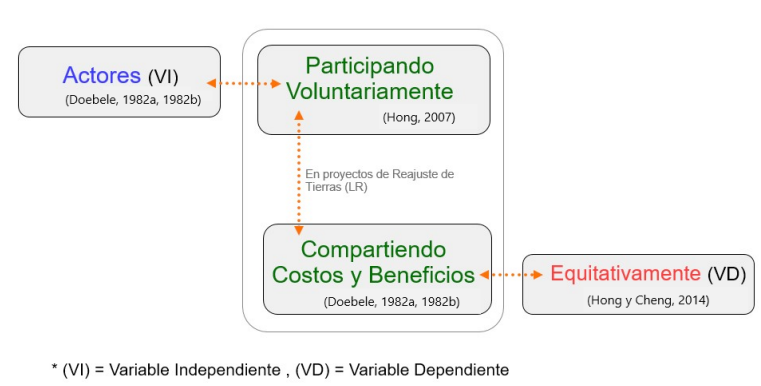

Figura 1. Hipótesis

Fuente: elaboración propia con base en Pinto (2005, pp. 89-104)

\section{Metodología y diseño} de la investigación

Los conceptos de la investigación fueron categorizados en variables (Anexo 1), medidas por indicadores tomados de Yilmaz, Çağdaş y Demir (2015). Algunos indicadores fueron reformulados para que se ajustaran mejor al alcance de esta investigación y otros fueron usados como los autores los formularon. En el Anexo 1 se observa cada uno de los indicadores incluidos, como preguntas en la encuesta o en las entrevistas clasificadas según el concepto o variable de análisis y el método de captura o instrumento utilizado.

\section{Estrategia de investigación}

Esta investigación fue desarrollada con una estrategia mixta: en primer lugar, una metodología de encuesta (Van Thiel, 2014) orientada a medir el balance entre los costos y los beneficios en los proyectos de reajuste de tierras en Colombia, que recolectó datos de los decretos y los documentos técnicos de soporte (DTS); cada proyecto tiene un instrumento legal que soporta su implementación, lo que facilita la revisión de documentación estandarizada. De esta manera fue posible comparar los resultados y descubrir patrones en los diferentes proyectos de reajuste de tierras. Se evaluó en términos de involucramiento de 
los actores y de recuperación de los costos en el momento en el que fue aprobado. Segundo, la estrategia incluyó entrevistas con personas clave que estuvieron involucradas en proyectos de reajuste de tierras específicos, para reunir información cualitativa de los seleccionados en la muestra. Las entrevistas sirvieron para triangular información y para explicar diferencias particulares, relacionadas con el contexto específico.

\section{Métodos de recolección de información}

Para recolectar la información cuantitativa se utilizaron los decretos que reglamentaban los proyectos. De acuerdo con el marco legal establecido en Colombia, todo reajuste de tierras dentro de un plan parcial debe cumplir requerimientos específicos, que son autorizados por decreto para cada uno. Esto permitió que la investigación tuviera un evento fijo en el tiempo, es decir, el momento de aprobación por decreto, con una serie de parámetros estandarizados presentes en cualquiera de las propuestas desarrolladas en todo el país. Así se estableció un punto de referencia estándar, aislado de las condicionantes de tiempos y lugares diferentes. Con esta información se calcularon los porcentajes de participación de los propietarios y el peso de los costos y beneficios de cada proyecto luego se analizaron los resultados en relación a la proporción y la distribución de esos porcentajes.

Los datos cualitativos usándose obtuvieron mediante un cuestionario semiestructurado para las entrevistas con los actores clave. Esos datos fueron usados para explicar en detalle variables que no podían ser medidas con la información de los decretos, como procesos de expropiación o compra de propiedades con anterioridad a la promulgación de los decretos. Era muy importante obtener información que pudiera validar o contradecir la teoría sobre el reajuste de tierras o que modificara los resultados del análisis cuantitativo. El manual de entrevistas se basó en los indicadores del marco teórico; algunas preguntas estaban orientadas a explicar situaciones particulares encontradas en los decretos, sobre todo si el proceso de participación fue voluntario y qué tipo de costos y beneficios fueron incluidos que no estaban en otros planes. También se entrevistó a expertos en planes parciales en Colombia para tener una visión más general y acceso a información adicional.

\section{Tamaño y selección de la muestra}

De un universo de 157 proyectos documentados en 2012 (Rodríguez, 2012), esta investigación incluyó los promulgados hasta mayo de 2015 de todo el país. Se reunió información de las páginas web municipales y mediante solicitudes formales a las oficinas de los municipios, de lo cual se obtuvo un total de 180 adoptados por Decreto. Entre ellos se hizo una selección estratificada aleatoria de treinta proyectos. La intención de la muestra estratificada era tener una representación proporcionada de las ciudades que han desarrollado proyectos de planes parciales en Colombia.

Como consecuencia, la muestra incluyó por lo menos uno de cada región para tener una mejor representación de la situación nacional (Anexo 5). Se observan los cálculos porcentuales de cada ciudad respecto a los planes adoptados y la distribución por región codificada por color, al igual que los tratamientos en los cuales se adoptaron.

Para la información cualitativa se hizo un muestreo intencional a partir de los proyectos seleccionados en la muestra aleatoria, con el objetivo de recoger datos de cinco proyectos. Por razones de tiempo y presupuesto, las entrevistas fueron realizadas en una sola ciudad con los funcionarios del Gobierno encargados, gerentes de proyectos 
de las compañías privadas que promovieron los proyectos y exfuncionarios que brindaron información desde una perspectiva diferente.

De los veinticinco proyectos que enviaron la documentación, cuatro no tenían la información mínima requerida, sobre todo relacionada con el análisis de costos y beneficios y el presupuesto de cada reajuste de tierras. De los veintiún proyectos que sí la tenían, dos fueron descartados; uno, porque los propietarios eran miembros de la misma compañía que lo estaba implementando y el otro, porque los porcentajes de los costos tuvieron que ser asumidos en algunos valores (los porcentajes de las ganancias, construcción, costos preoperativos, financieros y costos indirectos), lo que creó una gran incertidumbre en la distribución general. En consecuencia, la muestra efectiva para conducir la investigación fue de diecinueve, que representa una tasa de respuesta de $61 \%$, comprendidos por los proyectos denominados 01-Ciudadela el Rincón, 02-Simesa, 03-Altos del Poblado, 04-Everfit y 05-Vizcaya en Medellín; en Envigado, 06-Pavezco y 07-La Mina; en Bogotá, 11-La Pradera, 12-El Santuario, 13-La Palestina, 14-Clínica Shaio, 15-El Pedregal y 16-Hacienda Casablanca; en Pereira, 21-El Refugio y 22-Cabañuelas Santa Clara; 24-La Giralda en Dosquebradas; 27-Zonamérica y 29-Nueva Corea en Cali y, por último, de la generación antes del Decreto 2181 de 2006, 31-Naranjal.

\section{Métodos de análisis de datos}

\section{Métodos cuantitativos}

Los datos recolectados fueron subrayados en los documentos para mejorar la trazabilidad de la información e introducidos en una hoja de cálculo. Algunas celdas estaban formuladas de acuerdo con la teoría sobre reajuste de tierras, pero podían ser replanteadas si los textos especificaban que esas formulaciones eran diferentes para ese proyecto en particular. Los supuestos se explican en el Anexo 2 y el libro de formulación está incluido en el Anexo 3 junto con el formato de la hoja de cálculo. Una vez obtenidos todos los datos, la información fue transferida a una matriz de datos en un archivo aparte.

Primero se calculó el porcentaje de participación de los propietarios en cada proyecto. Luego se midió el incremento en el valor de la tierra de cada idea y fue comparado con los costos y beneficios de cada uno para revelar el porcentaje en proporción al incremento total del valor de la tierra. Este resultado fue contrastado entre los proyectos para probar la capacidad de la técnica del reajuste de tierras para recuperar los costos en diferentes contextos. Por último, los porcentajes de los ítems fueron cotejados en la herramienta de distribución de costos y beneficios. La variable dependiente de la investigación, "distribución equitativa de costos y beneficios", fue calculada como una proporción entre los costos y los beneficios que cada grupo de actores aportó y recibió en relación con el presupuesto total.

La información analizada brinda una idea del comportamiento de cada indicador y la distribución de la misma entre todos los proyectos. Para las variables nominales se utilizó una prueba chi-cuadrado. Se hizo una prueba de Anova para observar si las diferencias encontradas entre los beneficios de cada grupo de actores eran significativas.

Dado que los métodos cuantitativos se han conformado a partir de ecuaciones, en el libro de formulación que se encuentra en el Anexo 3 se pueden observar los procedimientos que dan fundamento a las ecuaciones utilizadas, de manera que puedan ser analizadas o controvertidas.

\section{Métodos cualitativos}

Las entrevistas fueron transcritas y codificadas de acuerdo con el manual de entrevistas (Anexo 4) y 
los indicadores. Cada código fue analizado para encontrar patrones en las entrevistas; se describió cada indicador tomado de diversas fuentes de información y se compararon esos resultados con los obtenidos en el análisis cuantitativo. Entre los proyectos escogidos, un predio fue seleccionado al azar para solicitar un certificado catastral; los certificados fueron analizados y subrayados para revisar si el propietario original del predio era quien estaba participando. Se cotejaron las fechas de los decretos con las fechas de compra o venta de los predios; así se reunió evidencia para determinar si el participante era el propietario original.

\section{Resultados de la investigación}

Una de las primeras apreciaciones que contrastan entre las personas entrevistadas y los proyectos evaluados es la percepción de que los planes parciales solo pueden existir en tratamientos de desarrollo o renovación urbana. Aunque este resultado no está directamente relacionado con el objeto de la investigación, es importante resaltarlo ya que, a diferencia de otros municipios, Bogotá desarrolla los planes parciales por el Decreto 436 de 2006, el cual limita el campo de acción a dichos tratamientos. Al ser la ciudad con mayor número de planes parciales, tiene una influencia en cómo se implementan en todo el país, al punto de que varios profesionales de otras ciudades, que han sido formados en la academia bogotana, dicen no poder adoptar planes en otros tratamientos.

Cuando la limitante solo existe en la ciudad de Bogotá, como se observa en el Anexo 5, existen planes en otros tratamientos como 02-Simesa, que es de redesarrollo, o Moravia, de mejoramiento integral, inclusive planes con varios manejos internos, como Bellomonte en Bogotá para consolidación y desarrollo.

\section{Acerca de la participación voluntaria}

Como regla general, todos los proyectos afirmaban que iban a motivar a los propietarios a participar en el desarrollo de las ideas, como parte del mecanismo de asociación que proponen los planes parciales. En este sistema se cuenta con una entidad gerencial a cargo y con la participación de los propietarios, quienes pueden contribuir con sus tierras, pero también con los costos del desarrollo. Sin embargo, como se muestra en la figura 2, la voluntariedad en la participación se desvanece a medida que se avanza.

¿Los propietarios están participando activamente?

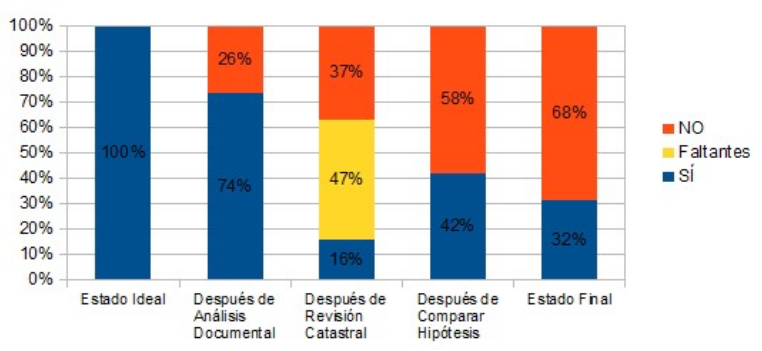

Figura 2. Participación voluntaria de propietarios

Fuente: elaboración propia

Una práctica común en Colombia es que los desarrolladores compren los predios en las primeras etapas de cualquier proyecto de construcción y en el caso de los reajustes de tierras no es diferente. Cinco de los diecinueve proyectos (26\%) ya mencionaban en los documentos que había compañías que estaban adquiriendo terrenos dentro del área del proyecto - la mayoría desarrolladores o uno de los propietarios que también estaba promoviendo la idea-. Esta información fue cotejada con los certificados de catastro y, en siete de las diez propiedades, el propietario original había vendido a compañías fachada. Resultados similares se obtuvieron al aplicar las hipótesis basadas en la teoría del reajuste de tierras: en once de los diecinueve proyectos, por lo menos un propietario original vendió su propiedad. 
Para definir el resultado de la investigación sobre la participación voluntaria, se contemplaron los resultados de las tres fuentes; si alguna de ellas demostraba que el propietario original había sido reemplazado, se consideraba que el proyecto no estaba englobando terrenos de acuerdo con lo planteado por el método de reajuste de tierras.

Con solo seis de los diecinueve proyectos (32\%) englobando terrenos según la metodología, se hizo una prueba chi-cuadrado para verificar si esa situación era representativa para todos los proyectos desarrollados en Colombia. La prueba confirmó que cuanta más información se recopilaba sobre los proyectos, más claro se hacía que los propietarios originales no estaban participando voluntariamente. En otras palabras, el porcentaje de participación voluntaria difiere significativamente en las etapas de los proyectos $(x 4,(1, N=86)=26,33 ; p=0,00)$.

Los entrevistados admitieron que existía compra de tierras por parte de inversores privados antes y durante el proceso de adopción de los planes parciales. Las entrevistas con encargados de las Oficinas de Planeación revelaron que en la mayoría de casos no había procedimientos establecidos para informar a los propietarios desde el principio, razón por la cual su participación solo se hacía al final del proceso de adopción, cuando los costos y beneficios ya habían sido calculados, lo que provocó disputas entre ellos. Como lo reportaron las entrevistas, cuando se presentaban tales conflictos, algunos propietarios vendían sus tierras y en otros casos se formulaban modificaciones al proyecto para resolverlas: cambios vinculados al poder político o de negociación de cada actor.

El resultado muestra que los propietarios no participan voluntariamente; buena parte de los participantes no son propietarios originales, sino que compran su participación en el proyecto. De acuerdo con la hipótesis del reajuste de tierras, la participación voluntaria de los propietarios es la característica que permite implementar la herramienta de recuperación de costos, lo que puede tener un efecto en el balance entre los costos y los beneficios.

Un importante resultado es que existen proyectos que están vinculando a los propietarios originales de la muestra. Un proyecto demostró, en todas las revisiones, que está vinculando a los propietarios originales (este hallazgo es importante porque es un ejemplo de que el reajuste de tierras puede ser participativo e inclusivo), que como método de englobe de terrenos puede contar con la participación de los propietarios originales y que se está haciendo en por lo menos uno de los proyectos en Colombia.

La consecuencia de encontrar un resultado adverso en relación con la participación voluntaria no significa ir contra la teoría, sino en que no existe voluntad real de participar, sea por el motivo que sea; esto hace que los procesos sean más demorados y costosos y elimina la posibilidad de financiar una mejor infraestructura, ya que parte de las ganancias tienen que destinarse a pagar un mayor valor por la tierra, como se observará a continuación.

\section{Acerca de la diferencia en el valor de la tierra}

Esta investigación ha reconstruido los presupuestos a partir del valor residual de la tierra, para poner a prueba la hipótesis de que al final de los proyectos, los propietarios van a recibir un lote más pequeño, pero con un mayor valor, lo que les motiva a participar. También se puso a prueba la capacidad del reajuste de tierras para movilizar el incremento en el valor de la tierra.

Dado que este valor no es comparable entre planes, se revisaron los porcentajes de documento del valor de la tierra en cada uno de los proyectos. En la figura 3 se observa la distribución del incremento en el valor de la tierra; todos los proyectos tienen un valor inicial de la tierra $100 \%$. 


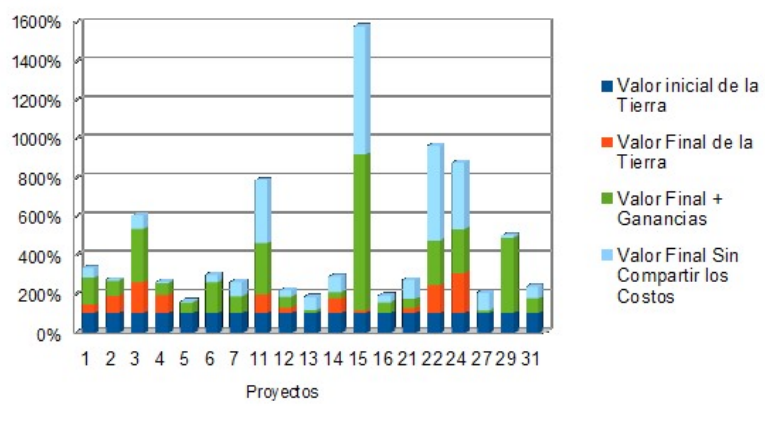

Figura 3. Incremento en el valor de la tierra (\%) Fuente: elaboración propia

En la tabla 4 se aprecia que el valor de la tierra se ha incrementado hasta en un $1479 \%$ para cubrir los costos de las cargas locales y generales y queda un excedente para los actores. El proyecto en el cual el incremento fue menor tuvo un balance positivo de $61 \%$ (los datos en la tabla 4 reflejan los valores incluido el $100 \%$ inicial). Esta información ayuda a soportar un argumento fundamental en el desarrollo de proyectos: el dilema de cubrir los costos de construir infraestructura. Algunos actores sostienen que no es posible cubrir esos costos porque, de ser así, serían transferidos al comprador final. Los hallazgos demuestran la afirmación de que esos costos son cubiertos por el incremento en el valor de la tierra, en especial porque, en el caso de los proyectos con reajuste de tierras, la posibilidad de incluir derechos de construcción adicionales, como parte de la herramienta para recuperar los gastos, permite sustentar los costos de la infraestructura y los servicios hasta el punto que el mercado inmobiliario lo permita.
Para probar la hipótesis de que después del reajuste los propietarios recibirán un lote de mayor valor, pero de menor tamaño, el valor del área resultante después de las cesiones fue calculado y comparado con el valor inicial de la tierra; un segundo cálculo incluyó el porcentaje de las ganancias de los proyectos en el valor final de la tierra. Si el resultado era mayor que el valor inicial del predio, los propietarios recibían más de su contribución inicial; por lo tanto estarían motivados a participar en los proyectos. Como se muestra en la figura 4, en el escenario inicial donde los propietarios no comparten las ganancias de los desarrolladores, la mayoría de los proyectos $(68 \%)$ les devolvería los terrenos con menor valor. Cuando el valor calculado incluye las ganancias de los desarrolladores, los resultados son opuestos: solo un $32 \%$ de los propietarios recibiría terrenos depreciados y la mayoría de los proyectos (68\%) retornaría, en teoría, lotes más valiosos a los poseedores de latifundio. Los valores promedio del incremento en el valor de la tierra fueron comparados con una prueba Anova de una vía y se halló que había una diferencia estadísticamente significativa entre los valores de la tierra $(F(3,72)=10,45 ; p=0,00)$. Una prueba Tukey post-hoc también reveló que, aunque la diferencia entre el valor inicial y el final de la tierra incluidas las ganancias era significativamente menor, estadísticamente hablando $(314 \pm 206 \% ; p=0,015)$, no había una diferencia entre el valor inicial y el final la tierra $(p=0,877)$. Esta diferencia puede ser causada por el hecho de que algunos de los proyectos

Tabla 4. Incremento en el valor de la tierra. Datos porcentuales

\begin{tabular}{|l|r|r|r|r|r|}
\hline Incremento en el valor de la tierra & \multicolumn{1}{|c|}{ Promedio } & Mediana & Desviación estándar & \multicolumn{1}{c|}{ Mínimo } & \multicolumn{1}{c|}{ Máximo } \\
\hline Valor inicial de la tierra & 100 & 100 & 0,00 & 100 & 100 \\
\hline Valor final de la tierra & 152 & 126 & 64,12 & 100 & 305 \\
\hline Valor final incluidas las ganancias & 314 & 255 & 205,64 & 116 & 919 \\
\hline Valor final sin compartir los costos & 447 & 275 & 367,97 & 161 & 1579 \\
\hline * Valores porcentuales (\%) & & & &
\end{tabular}

Fuente: elaboración propia 
no establecían un valor inicial de la tierra; una prueba realizada excluyó esos proyectos con similares resultados $(F(3,65)=8,23, p=0,00)$ y $(p=0,924)$ entre el valor inicial y el final de la tierra. Dado que la diferencia no fue significativa, era posible que los propietarios no estuvieran motivados a participar en los proyectos de reajuste de tierras.

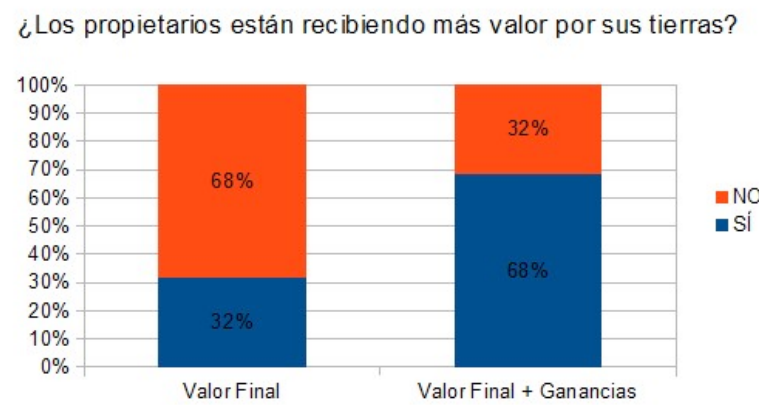

Figura 4. Incremento en el valor de la tierra. Motivación para participar

Fuente: elaboración propia analizados. Aquellos que presentan una distribución diferente no incluyen los costos de construir los edificios (proyectos 13 y 27) o los costos de construcción son bajos, como en el proyecto 05 , porque gran parte del área construida conforma edificaciones que serán renovadas y no demolidas. Varios están autofinanciados por los productos inmobiliarios que venden; esto es posible debido a la forma como se desarrollan los proyectos en Colombia mediante un fideicomiso, que permite la interacción entre actores y libera la carga de cubrir los costos al vender los productos inmobiliarios previos al inicio de la construcción. Dos incluyen subsidios: uno es completamente subsidiado por el Gobierno, orientado a construir vivienda social y en el otro, el propietario, que también es el desarrollador, quiere conservar parte del área para su propio uso y asume el costo.

Para concluir, los costos y beneficios están incluidos en los presupuestos de los proyectos seleccionados en una forma similar. Algunos reflejan condiciones particulares que son disímiles; sin embargo, esas condiciones son contempladas como parte de las posibilidades que ha encontrado la teoría sobre reajuste de tierras. Las entrevistas confirmaron la información hallada en los documentos con una particular diferencia en la manera como se circunscribe el tiempo en los costos, ya que los entrevistados del sector público reciben y manejan modelos estáticos que no contemplan el valor del tiempo como una variable, mientras las entrevistas con actores privados mostraron que utilizan modelos dinámicos que en algunos casos les permiten incluir la variable tiempo, la cual es fundamental en proyectos de varios años como los desarrollos urbanos de los planes parciales.

\section{Acerca de los beneficios recibidos por grupo de actores}

De acuerdo con los entrevistados existen dos maneras de compartir el valor de la tierra: la primera es movilizar el incremento en el valor de de los costos muestra un patrón similar en la mayoría de los proyectos de reajuste de tierras 


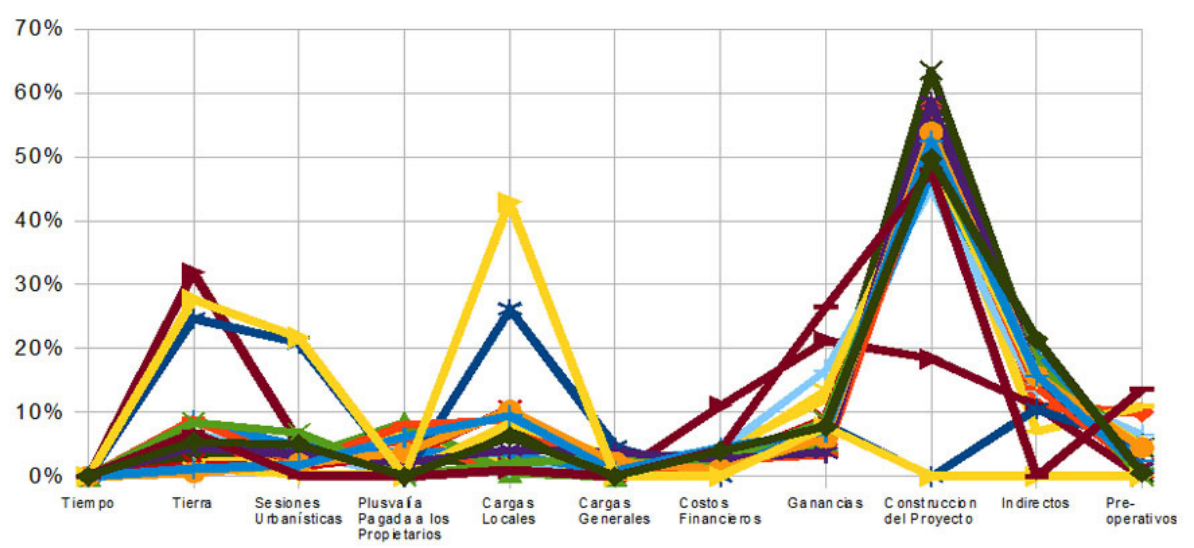

Figura 5. Distribución de costos

Fuente: elaboración propia

la tierra para proveer espacios públicos y cubrir los costos de la construcción de infraestructura y los equipamientos públicos. La segunda es capturarlo por medio del cobro de la contribución por plusvalía en los municipios que lo tienen implementado. No existe un proceso de verificación para evaluar si hay una distribución equitativa de los beneficios, una vez el proyecto es decretado. Las entidades municipales solo se ocupan de revisar que los costos que deben cubrir en el desarrollo estén incluidos en el decreto, para que los desarrolladores cumplan con la ley.

¿Qué porcentaje fue capturado por cada actor?

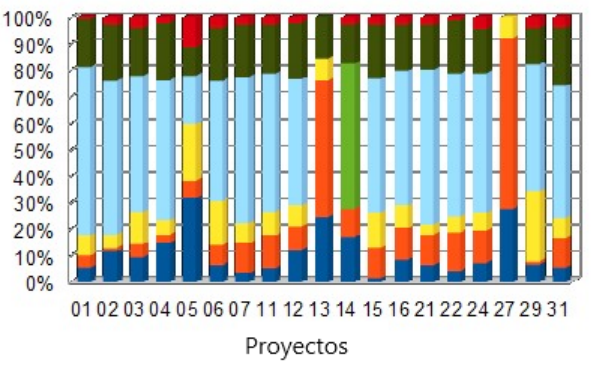

- Financieros - No Actores (contratistas) $=$ No Actores (Compradores u otros)
Fiducia Inversores Desarrolladores - Público - Propietarios

Figura 6. Beneficios por actor

Fuente: elaboración propia

Los costos fueron asignados a cada grupo de actores de acuerdo con las hipótesis planteadas en el Anexo 2. Algunos de esos actores no son accionistas del proyecto, ya que no tienen participación en sus reajustes o beneficios finales y su interacción es posible gracias a encargo fiduciario. Como se muestra en la figura 6 , el porcentaje que recibe cada grupo de actores es similar en todos los proyectos, a excepción de aquellos que no incluyen los costos de construcción (proyectos 13 y 27), el que incluye parte de los costos de construcción (proyecto 05) y en el cual el promotor y propietario usará parte del área para su objeto social (proyecto 14). La mayoría de los beneficios fue capitalizada por los compradores de los productos inmobiliarios, ya que son quienes finalmente financian los proyectos.

\section{Acerca de la distribución equitativa} del valor de la tierra

Al comparar la figura 7 con la figura 8 se pueden observar algunas diferencias; la más visible es que los beneficios recibidos por los desarrolladores (en color amarillo) son mayores de lo que deben ser al disminuir los beneficios del público (en color naranja) y en una menor proporción y los beneficios de los propietarios (color azul), es decir, los desarrolladores capturan más beneficios de los que les corresponden. 


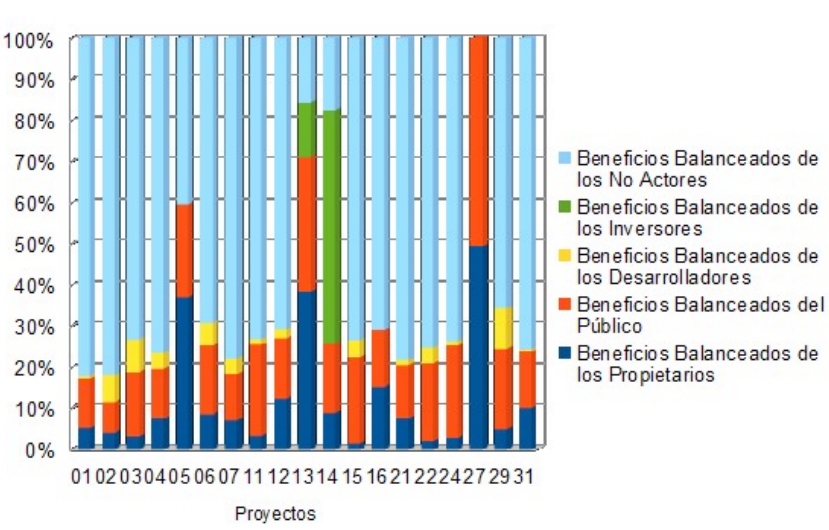

Figura 7. Beneficios balanceados por actor Fuente: elaboración propia

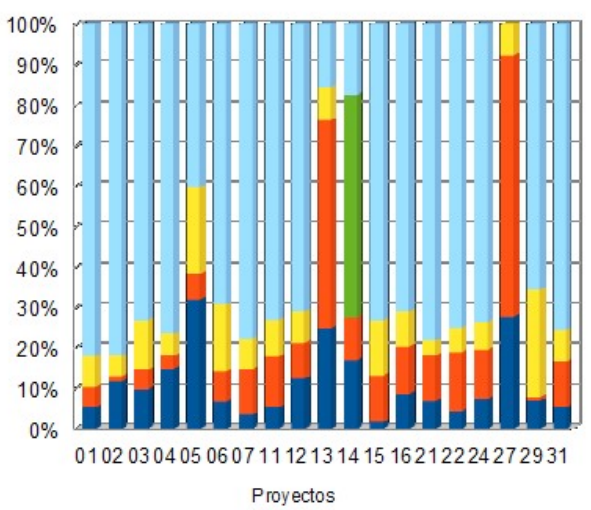

Figura 8. Beneficios por grupo de actores Fuente: elaboración propia

La misma comparación puede hacerse entre las tablas 5 y 6 , en este caso respecto a los resultados del público con el de los desarrolladores y un intercambio entre ellos. Para ser exactos, se
Beneficios de los No Actores Beneficios de los Inversores

Beneficios de los Beneficios del Público

- Beneficios de los Propietarios hizo una deducción para encontrar la diferencia aritmética entre esos valores en cada uno de los proyectos y un análisis descriptivo con las diferencias (tabla 7).

Los resultados mostraron que los propietarios reciben en promedio un $1 \%$ menos $(\mathrm{SD}=7,51)$ de lo que deberían recibir; el público está recibiendo $5 \%$ menos $(\mathrm{SD}=9,00)$ de lo que se supone que le corresponde y los inversores también están recibiendo menos beneficios $(\mathrm{M}=-0,79 ; \mathrm{SD}=2,99)$. Los desarrolladores, por el contrario, están recibiendo $5 \%$ más $(\mathrm{SD}=5,38)$ de lo que deberían.

Con estos resultados se hizo una prueba para ver si las diferencias entre los promedios de beneficios de cada grupo de actores eran estadísticamente significativas para llegar a conclusiones generalizables para todos los proyectos de la muestra. Una prueba de una vía Anova fue conducida en SPSS con una prueba Tukey post-hoc para comparar los promedios entre los grupos. El grupo de actores fue la variable independiente y la diferencia en los beneficios, la dependiente.

Hubo una diferencia estadísticamente significativa entre los grupos de actores según lo determinado por la prueba de Anova de una vía $(F(4,90)=10.148 ; p=0,000)$. La prueba Tukey post-hoc reveló que los desarrolladores tuvieron

Tabla 5. Distribución de las contribuciones. Datos porcentuales

\begin{tabular}{|l|l|l|l|l|l|}
\hline \multicolumn{1}{c|}{ Actores } & \multicolumn{1}{c|}{ Promedio } & \multicolumn{1}{c|}{ Mediana } & Desviación estándar & \multicolumn{1}{c|}{ Mínimo } & \multicolumn{1}{c}{ Máximo } \\
\hline Contribución de los propietarios & 13,16 & 8,00 & 14,32 & 2,00 & 49,00 \\
\hline Contribución pública & 21,32 & 20,00 & 9,79 & 11,00 & 51,00 \\
\hline Contribución de los desarrolladores & 3,53 & 1,00 & 4,27 & 0,00 & 14,00 \\
\hline $\begin{array}{l}\text { Contribución de los inversores } \\
\text { Contribución de la fiducia }\end{array}$ & 4,47 & 0,00 & 16,05 & 0,00 & 69,00 \\
\hline * & 57,53 & 71,00 & 27,22 & 0,00 & 82,00 \\
\end{tabular}

Fuente: elaboración propia 
Tabla 6. Beneficios balanceados. Datos porcentuales

\begin{tabular}{|c|c|c|c|c|c|}
\hline Actores & & Mediana & Desviación estándar & Mínimo & Máximo \\
\hline $\begin{array}{l}\text { Beneficios balanceados de los } \\
\text { propietarios }\end{array}$ & 12,00 & 8,00 & 13,71 & 1,00 & 49,00 \\
\hline Beneficios balanceados del público & 18,89 & 17,00 & 9,67 & 7,00 & 51,00 \\
\hline $\begin{array}{l}\text { Beneficios balanceados de los } \\
\text { desarrolladores }\end{array}$ & 2,68 & 1,00 & 2,98 & 0,00 & 10,00 \\
\hline Beneficios balanceados de los inversores & 3,68 & 0,00 & 13,25 & 0,00 & 57,00 \\
\hline Beneficios de los no actores & 62,68 & 73,00 & 24,83 & 0,00 & 82,00 \\
\hline * Valores porcentuales (\%) & & & & & \\
\hline
\end{tabular}

Fuente: elaboración propia

Tabla 7. Diferencia entre los beneficios (balanceados contra recibidos). Datos porcentuales

\begin{tabular}{|l|l|l|l|l|l|}
\multicolumn{1}{c}{ Actores } & \multicolumn{1}{c|}{ Promedio } & \multicolumn{1}{c|}{ Mediana } & Desviación estándar & \multicolumn{1}{c|}{ Mínimo } & \multicolumn{1}{c}{ Máximo } \\
\hline Diferencia de los propietarios & $-1,11$ & 0,00 & 7,51 & $-22,00$ & 8,00 \\
\hline Diferencia del público & $-5,05$ & $-6,00$ & 9,00 & $-19,00$ & 19,00 \\
\hline Diferencia de los desarrolladores & 6,89 & 7,00 & 5,38 & $-1,00$ & 21,00 \\
\hline Diferencia de los inversores & $-0,79$ & 0,00 & 2,99 & $-13,00$ & 0,00 \\
\hline *Valores porcentuales (\%) & & & & &
\end{tabular}

Fuente: elaboración propia

una diferencia estadísticamente notable frente a los otros actores: los propietarios, $(6,89 \pm 8,0 \%$; $p=0,001)$; al público $(6,89 \pm 11,9 \% ; p=0,000)$; a los inversores $(6,89 \pm 7,7 \% ; p=0,001)$; a los actores no participantes $(6,89 \pm 6,9 \%$; $p=0,005)$. Sin embargo, entre los otros actores no hubo una diferencia estadísticamente significativa.

Los resultados de esta prueba confirman el patrón observado en las figuras y tablas: los desarrolladores están recibiendo más beneficios de los que deberían y, por tanto, desbalancean la distribución de los costos y los beneficios en los proyectos de reajuste de tierras, lo que genera una participación no equitativa al compartir el incremento en el valor de la tierra entre los actores.

\section{Conclusiones}

\section{Argumentos clave y lecciones aprendidas}

La configuración institucional que el reajuste de tierras tiene en Colombia difiere del marco teórico aquí probado, sobre todo porque en el país las dos características principales del reajuste de tierras son separadas por el método de englobe y la herramienta de recuperación de costos. Mientras la estrategia de recuperación de costos es usada como parte de la configuración general para todos los planes parciales, el método de inclusión, con la participación voluntaria de los propietarios, es solo una opción y es la menos usada de todas. Estas condiciones pueden influenciar la implementación de los proyectos con reajuste de tierras porque, de acuerdo con Hong (2007), el método de englobe del reajuste de tierras es lo que permite que la herramienta 
de recuperación de costos sea más efectiva para conservar bajos precios de transacción. Será necesario un análisis más detallado para diagnosticar la fase de implementación de los proyectos con reajuste de tierras en Colombia y así medir el impacto del actual marco institucional.

Los resultados han mostrado que los propietarios originales están vendiendo sus propiedades y de esa manera no participan en el proceso de reajuste de tierras. Estos resultados han sido probados y se determinó que existe una diferencia estadísticamente significativa entre el estado inicial de acuerdo con los decretos y lo que realmente sucede en el desarrollo de los proyectos. Desarrolladores e inversores han adquirido terrenos para desarrollar los proyectos; esta es una práctica común en Colombia que, de acuerdo con Turk (2008), socava un principio básico del reajuste de tierras —el método de englobe- que es diferente de cualquier otro método, ya que al asociar a los propietarios originales, se mantendrán bajos costos de transacción. Sería importante analizar cuál es el impacto del proceso de adquisición de tierras de los planes parciales en los resultados financieros de los proyectos con reajuste de tierras.

En todos los proyectos, el valor de la tierra se ha incrementado lo suficiente como para cubrir todos los costos y dejar ganancias a los actores. La tierra aumentó su valor en diferentes porcentajes, entre un $61 \%$ y un $1479 \%$ según diferentes factores como la ubicación, el uso futuro y otros aspectos inherentes que hacen de cada lote un proyecto único y diferente. Esto coincide con el argumento que afirma que la tierra incrementa su valor por acciones de diferentes interventores, además de las acciones puntuales del propietario (Smolka, 2013a).

En los casos de participación voluntaria, es la decisión de los propietarios de participar en el reajuste lo que ha incrementado el valor de la tierra. Este hecho puede ser investigado con mayor detalle, pues ayudará a profundizar los conocimientos sobre cómo se incrementa el valor de la tierra y quiénes generan ese aumento.

Esta investigación ha contribuido a sustentar los argumentos a favor de abarcar los costos de infraestructura y servicios en los proyectos. Todos ellos lo han hecho, por lo que se beneficiará a la población al incluir la construcción de la estación de buses tipo BRT (bus rapid transit Transmilenio); al incluir estas cargas, los desarrolladores de estos proyectos respaldan con sus acciones la idea de financiar los costos de infraestructura. Esto puede ser útil en ciudades en donde los desarrolladores son renuentes, con el argumento de que estos serán transferidos a los compradores finales. Esta investigación ha contribuido a evidenciar casos en los que tales costos son asumidos por el incremento en el valor de la tierra.

Los resultados han mostrado que los propietarios no están siendo motivados a participar en los reajustes de tierras porque el beneficio que reciben después no es significativamente mayor que el valor que aportan con su tierra. La ausencia de una diferencia estadísticamente significativa entre el valor inicial y el valor final de la tierra soporta este hallazgo. Por el contrario, la diferencia estadísticamente relevante entre el valor inicial de la tierra y el incremento en el valor de la tierra, incluidas las ganancias, brinda una línea de acción, pues los desarrolladores deben compartir las ganancias para motivar a los propietarios a participar. Esta situación puede suceder debido a que algunos propietarios son también los desarrolladores que compraron su participación en el proyecto, por lo que reciben beneficios como propietarios y también como desarrolladores. La aproximación teórica a esta situación es que, si los desarrolladores comparten las ganancias con los propietarios, estos últimos estarán motivados a participar (Sorensen, 2007), por eso no existiría la necesidad de comprar los terrenos de los propietarios originales y los costos de transacción 
se mantendrían bajos. Investigaciones adicionales podrían evaluar cuál es la influencia del valor que reciben por la tierra en la decisión de los propietarios de participar o no en proyectos de reajuste de tierras.

Los costos y beneficios incluidos en los presupuestos calculados tienen una distribución percentil similar en todos los proyectos, excepto por aquellos que no abarcan el costo de construir los edificios. No hay una diferencia observada en la distribución de los costos entre proyectos de diferentes tratamientos; los proyectos de redesarrollo tienen una distribución similar que los de desarrollo o de otros tratamientos. En este sentido, los que no incluyeron los costos de construcción pudieron haber causado una distorsión en los valores promedio de cada variable; sin embargo, era importante contemplarlos, ya que brindan una perspectiva general de todos los reajustes de tierras sin afectar los resultados de la pregunta principal de la investigación, o sea, tienen resultados similares a los demás en relación con la distribución de los beneficios. Investigaciones posteriores, con una muestra diferente que separe los proyectos que abarcan los costos de construcción de los que no, son necesarios para comparar los resultados.

La mayoría de los proyectos no se basaba en subsidios del Gobierno para cubrir los costos; solo uno de ellos fue completamente subsidiado, pues se pretendía proveer vivienda social como una forma del Gobierno de intervenir el mercado cuando existe un asunto de interés público, sobre todo en Colombia, en donde la vivienda es un bien meritorio y el Estado debe garantizar su provisión. Aparte de ese caso, todos los proyectos fueron autofinanciados por la venta de los productos inmobiliarios con los que intentaban pagar por los costos y dejar un desarrollo rentable. Es un buen aprendizaje entender que un proyecto puede ser financiado usando el mercado inmobiliario y otras herramientas como el sistema fiduciario para alcanzar esa meta.

Por último, los actores de los proyectos decretados con reajuste de tierras en Colombia no están compartiendo el incremento en el valor de la tierra de una manera equitativa, pues hay una diferencia estadísticamente significativa entre grupos de actores, provocada por las acciones de los desarrolladores que se están beneficiando más de lo que contribuyen. Las razones que pueden influenciar estos resultados deberán ser tema de futuras investigaciones.

Durante esta investigación se encontraron algunas distorsiones: actores que son desarrolladores y al mismo tiempo propietarios, actores que compran su participación y desplazan a propietarios originales, escasa claridad en las contribuciones de cada actor o cambios en la configuración inicial de los proyectos debidos a factores de tiempo y restricciones.

El objetivo de esta investigación fue comparar el proceso de reajuste de tierras en Colombia con la teoría que soporta esta herramienta de gestión y proveer evidencia que pueda influenciar la manera como está siendo implementado. Coincide con el enfoque de la estrategia Pilar (Hong y Tierney, 2014), que apuntan hacia un reajuste de tierras más participativo y balanceado entre sus actores.

\section{Recomendaciones}

La inclusión de los propietarios originales en la implementación es un elemento fundamental del reajuste de tierras. Es un proceso que requiere un enfoque diferente al que se utiliza tradicionalmente en Colombia y puede traer grandes beneficios en el marco temporal de los proyectos, ya que el trámite de adquisición de tierras actual es muy demorado, sobre todo en proyectos de 
redesarrollo, que pueden traer equidad económica y social, no solo financiera.

Los municipios deben crear metodologías para evaluar los procesos de implementación de los planes parciales más allá de la adopción del decreto; esto culmina un proceso de colaboración que, en algunos casos, tomó varios años, pero no es sino hasta que el proyecto es construido que los beneficios para todos los ciudadanos se materializan, por lo cual es importante que las municipios acompañen el proceso de desarrollo y construcción. Es importante que los funcionarios municipales compartan conocimientos entre ellos durante todo el proceso, que evalúen y estudien casos, para que puedan detectar errores, los corrijan a tiempo y generen un conocimiento colectivo que mejore el proceso a largo plazo. También puede ser beneficioso compartir conocimiento entre municipios, ya que el marco legal para el reajuste de tierras es el mismo para todo el territorio nacional. Esta forma de comunicación puede nutrir los procesos locales de implementación y mejorar las regulaciones locales.

En el proceso de diseño de los proyectos existen algunas tareas que pueden mejorar el resultado general, como hacer avalúos del valor inicial de la tierra y contrastarlos con el valor final para revisar si los reajustes que van a recibir los propietarios son más valiosos que su contribución inicial y así motivarlos a participar.

Examinar los costos del tiempo con modelos dinámicos puede dar una percepción real, en especial si uno de los problemas reportados es el largo proceso de implementación. Un mejor entendimiento de los costos y beneficios en un marco de tiempo específico brinda un nuevo lineamiento que puede ser incluido en los decretos.

Por último, es importante controlar y evaluar los beneficios y las ganancias recibidos, ya que mantener el balance es una tarea crucial y generar equidad es fundamental para un país que es uno de los más desiguales del mundo.

\section{Agradecimientos}

Producto del trabajo de investigación "Testing Land Readjustment in Colombia: The Equitable Share between Stakeholders", apoyado por el Netherlands Fellowship Program-Nuffic, mediante la beca número NFP-MA.14/35. Fue desarrollada por el autor en Erasmus Universiteit Rotterdam, como parte de un programa de maestría entre septiembre de 2014 y octubre de 2015.

\section{Referencias}

Alfonso, Ó. A. (2003, septiembre). De Nagoya a Armenia. El reajuste de tierras en Japón y en Colombia. Ponencia presentada en el V Seminário Internacional da Lares. Mercado imobiliário: novas realidades, conceitos e processos, Sao Paulo, Latin American Real Estate Society (Lares).

Alterman, R. (2007). Much More than Land Assembly: Land Readjustment for the Supply of Urban Public Services. En Y. Hong y B. Needham (eds.), Analyzing Land Readjustment: Economics, Law, and Collective Action (pp. 57-86). Cambridge: Lincoln Institute of Land Policy.

Alterman, R. (2012). Land Use Regulations and Property Values: The "Windfalls Capture" Idea Revisited. En N. Brooks, K. Donaghy y G. Knaap (eds.), The Oxford Handbook of Urban Economics and Planning (pp. 755-786). Oxford: Oxford University Press.

Balakrishnan, S. (2018). Land Cooperatives in India: New Challenges of 21st Century Land Readjustment. En UN-Habitat, Global Experiences in Land Readjustment (pp. 119-139). Kenya: UN-Habitat. 
Borrero, Ó. (2007). The Effects of Land Policy on Urban Land Prices in Bogota. Cambridge: Lincoln Institute of Land Policy.

Centro de Memoria Histórica. (2012). ;Basta ya! Colombia: memorias de guerra y dignidad. Bogotá: Imprenta Nacional.

Colombia, Congreso de la República. (1989). Ley 9 de 1989, "Por la cual se dictan normas sobre planes de desarrollo municipal, compraventa y expropiación de bienes y se dictan otras disposiciones". Bogotá: Diario Oficial, núm. 38.650, 11 de enero de 1989.

Colombia, Congreso de la República. (1997). Ley 388 de 1997, "Por la cual se modifica la Ley $9^{a}$ de 1989 y la Ley $3^{a}$ de 1991 y se dictan otras disposiciones". Bogotá: Diario Oficial, núm. 43.127, 24 de julio de 1997.

Departamento Administrativo Nacional de Estadística [DANE]. (2010). Proyecciones nacionalesy departamentales de población 2005-2020. Recuperado de http://www.dane.gov.co

Doebele, W. A. (1982a). Introduction. En W. A. Doebele (ed.), Land Readjustment: A Different Approach to Financing Urbanization (pp. 1-10). Lexington: Lexington Books.

Doebele, W. A. (1982b). Synopsis. En W. A. Doebele (ed.), Land Readjustment: A Different Approach to Financing Urbanization (pp. 11-28). Lexington: Lexington Books.

Doebele, W. A. (2007). Foreword. En Y. Hong y B. Needham (eds.), Analyzing Land Readjustment: Economics, Law, and Collective Action (pp. vii-xiv). Cambridge: Lincoln Institute of Land Policy.

Grimes Jr., O. F. (1982). Financing Urban Infrastructure in Developing Countries. En W. A. Doebele (ed.), Land Readjustment: A
Different Approach to Financing Urbanization (pp. 207-212). Lexington: Lexington Books.

Hagman, D. G., y Misczynski, D. J. (1977). Windfalls for Wipeouts: Land Value Recapture and Compensation. Chicago: American Planning Association.

Hong, Y. (2007). Assembling Land for Development: Issues and Opportunities. En Y. Hong y B. Needham (eds.), Analyzing Land Readjustment: Economics, Law, and Collective Action (pp. 3-34). Cambridge: Lincoln Institute of Land Policy.

Hong, Y., y Brain, I. (2012). Land Readjustment for Urban Development and Post-Disaster Reconstruction. Land Lines, 24(1), 2-9.

Hong, Y., y Cheng, A. (2014). The Symmetry between Land Value Creation and Sharing: How Land Value Sharing could Help Finance New City Development. Recuperado de https://www.dropbox.com/s/33utgzomkzaxp4g/Hong_Cheng2014.pdf?dl=0

Hong, Y., y Tierney, J. (2014). Making Land Readjustment Participatory and Inclusive. Recuperado de https://www.dropbox.com/s/cfyxca43c0syg6r/HongTierney2013.pdf?dl=0

Leeruttanawisut, K., y Rabé, P. (2018). Revisiting Land Sharing in Bangkok, Thailand: The Sengki Case. En UN-Habitat, Global Experiences in Land Readjustment (pp. 84-97). Kenya: UN-Habitat.

Lungo, M. (ed.). (2004). Grandes proyectos urbanos. San Salvador: Universidad Centroamericana José Simeón Cañas.

Maldonado, M. M., Pinilla, J. F., Rodríguez, J. F., y Valencia, N. (2006). Planes parciales, gestión asociada y mecanismos de distribución equitativa de cargas y beneficios en el sistema urbanistico colombiano: marco jurídico, conceptos básicos 
y alternativas de aplicación. Bogotá: Lincoln Institute of Land Policy.

Needham, B. (2007). The Search for Greater Efficiency: Land Readjustment in the Netherlands. En Y. Hong y B. Needham (eds.), Analyzing Land Readjustment: Economics, Law, and Collective Action (pp. 115-132). Cambridge: Lincoln Institute of Land Policy.

Norbu, G. (2018). Land Pooling in Thimphu, Bhutan. En UN-Habitat, Global Experiences in Land Readjustment (pp. 112-128). Kenya: UN-Habitat.

Payne, G. K. (2002). Introduction. En G. K. Payne (ed.), Land, Rights and Innovation: Improving Tenure Security for the Urban Poor (pp. 3-22). Londres: ITDG publishing.

Pinilla, J. (2018). A New Approach to Urban Renewal in Bogotá: The Fenicia Project. En UN-Habitat, Global Experiences in Land Readjustment (pp. 36-55). Kenya: UN-Habitat.

Pinto, A. C. (2005). La distribución equitativa de cargas y beneficios en Colombia y algunas referencias sobre la experiencia de Japón. Ciudad y territorio: estudios territoriales (143), 89-104.

Rodríguez, J. F. (2012). Land Readjustment $(L R / P)$ Experience in Colombia. Final Report. Bogotá: UN Habitat.

Rojas, M. C., y Rave, B. (2013). Reajuste de tierras en Medellin-Colombia. Cambridge: Lincoln Institute of Land Policy.

Smolka, M. O. (2013a). International and Latin American Experiences. En M. O. Smolka (ed.), Implementing Value Capture in Latin America: Policies and Tools for Urban Development (pp. 13-20). Cambridge: Lincoln Institute of Land Policy.
Smolka, M. O. (2013b). Latin American Urbanization and the Case for Value Capture. En M. O. Smolka (ed.), Implementing Value Capture in Latin America: Policies and Tools for Urban Development (pp. 4-12). Cambridge: Lincoln Institute of Land Policy.

Smolka, M. O. e Iracheta, A. (2000). Mobilizing Land Value Increments to Provide Service Land for the Poor. Cambridge: Lincoln Institute of Land Policy.

Smolka, M. O., y Amborski, D. (2000). Value Capture for Urban Development: An Inter-American Comparison. Cambridge: Lincoln Institute of Land Policy.

Sorensen, A. (2007). Consensus, Persuasion and Opposition: Organizing Land Readjustment in Japan. En Y. Hong y B. Needham (eds.), Analyzing Land Readjustment: Economics, Law, and Collective Action (pp. 89-114). Cambridge: Lincoln Institute of Land Policy.

Turk, S. S. (2008). An Examination for Efficient Applicability of the Land Readjustment Method at the International Context. Journal of Planning Literature, 22(3), 229-242.

Van Thiel, S. (2014). Research Methods in Public Administration and Public Management: An Introduction. En Routledge Masters in Public Management Series: 11. Londres: Routledge Ltd.

Yilmaz, A., Çağdaş, V., y Demir, H. (2015). An Evaluation Framework for Land Readjustment Practices. Land Use Policy, 44, 153-168.

Zeluel, A., y Hong, Y-H. (2014). Urban Redevelopment. Experience in Addis Ababa, Ethiopia. Recuperado de https://www.dropbox.com/s/ k316lh2a8red67p/Zeluel-2014.pdf?dl=0 


\section{Anexos}

\section{Anexo 1. Compared Variables between Yilmaz, Çagdas and Demir (2015) and the Operationalized Indicators}

\begin{tabular}{|c|c|c|}
\hline Variables & Indicators & Indicators (yilmaz, çagdas, et al., 2015) \\
\hline \multicolumn{2}{|c|}{ Voluntary participation of landowners } & \\
\hline \multicolumn{3}{|c|}{$\begin{array}{l}\text { Participation of landowners is a direct inclusion of original owners in the decision-making process of land readjustment projects. Without } \\
\text { buying out landowners. And is fundamental for the implementation of a Ir project. }\end{array}$} \\
\hline \multirow{7}{*}{ Direct inclusion } & $\begin{array}{l}\text { Are the landowners participating in the decision-making } \\
\text { process? }(\mathrm{y} / \mathrm{n})\end{array}$ & \multirow{2}{*}{$\begin{array}{l}\text { (1) does participation ensured in the projects } \\
(y / n) \text {, }\end{array}$} \\
\hline & Percentage of landowners participating & \\
\hline & What it is the decision-making process like? & $\begin{array}{l}\text { (2) if yes, what is the participation type (direct } \\
\text { or indirect)? }\end{array}$ \\
\hline & $\begin{array}{l}\text { "the Ir projects are explained in details to the landowners. } \\
(y / n) "\end{array}$ & \multirow{3}{*}{$\begin{array}{l}\text { The Ir projects are explained in details to the } \\
\text { landowners. }(\mathrm{y} / \mathrm{n})\end{array}$} \\
\hline & Number of meetings hold with landowners & \\
\hline & Kind of decisions taken by the landowners & \\
\hline & $\begin{array}{l}\text { "it is possible for land ownership disputes to cause delays } \\
\text { in projects? }(\mathrm{y} / \mathrm{n}) \text { " }\end{array}$ & $\begin{array}{l}\text { It is possible for land ownership disputes to } \\
\text { cause delays in projects? }(\mathrm{y} / \mathrm{n})\end{array}$ \\
\hline \multirow{4}{*}{ Original landowners } & $\begin{array}{l}\text { Is the property registry reflecting expropriation or } \\
\text { compulsory acquisition before the project? }(y / n)\end{array}$ & $\begin{array}{l}\text { The technical processes of Ir have adequate } \\
\text { standards }(y / n) \text {. }\end{array}$ \\
\hline & Is the government a landowner? $(y / n)$ & \\
\hline & $\begin{array}{l}\text { Is there any "measure for landowners to remain } \\
\text { after the project? }(\mathrm{y} / \mathrm{n}) \text { " }\end{array}$ & $\begin{array}{l}\text { Is there any legal measure for landowners to } \\
\text { remain after the project? }(\mathrm{y} / \mathrm{n})\end{array}$ \\
\hline & $\begin{array}{l}\text { Where there transparency issues in the land registration } \\
\text { history? }(y / n)\end{array}$ & $\begin{array}{l}\text { (1) every step is transparent in } \operatorname{Ir}(y / n),(2) \text { list of } \\
\text { the nontransparent processes. }\end{array}$ \\
\hline \multirow[t]{2}{*}{ No buying out } & $\begin{array}{l}\text { "is there any measure to reduce or prevent plot } \\
\text { speculation? }(y / n) \text {. If yes, list of the available measures" }\end{array}$ & $\begin{array}{l}\text { Is there any measure to reduce or prevent plot } \\
\text { speculation? }(y / n) \text {. If yes, list of the available } \\
\text { measures }\end{array}$ \\
\hline & $\begin{array}{l}\text { "is there any solution for landowners who want to leave } \\
\text { the project? }(y / n) \text { if yes, list them." }\end{array}$ & $\begin{array}{l}\text { Is there any solution for landowners who want } \\
\text { to leave the project? }(\mathrm{y} / \mathrm{n}) \text { if yes, list them. }\end{array}$ \\
\hline
\end{tabular}

Cost recovery is the process of self-financing a land readjustment by valuating the initial plots of land and calculating the future value after the project, the difference should be used to reserve part of the land for allocation of services and infrastructure needed for the project, selling part of the land to pay for the installation of those services and the infrastructure and giving back to landowners the appreciated residual land distributed by the same proportion they contributed.

Is the project calculating the initial value of land? What is the percentage on it?

Valuation
Is the project calculating the final value of land? What is the percentage on it?
(1) list of the "appraisal' methods. (2) assessment of the accuracy $(\mathrm{y} / \mathrm{n})$

The data which are used in the Ir projects such as planning and valuation has adequate quality 


\section{Cost recovery tool}

Is the cost of time included? What is the percentage on it?

Is the cost of land included? What is the percentage on it?

Is the cost of land reserved for public use included? What is the percentage on it?

Is the cost of in-site services and infrastructure included? What is the percentage on it?

Costs included

Benefits included

\section{Land returned}

Is the cost of off-site services and infrastructure included? What is the percentage on it?

Are financial costs included? What is the percentage on it?

Are profits included as costs? What is the percentage on it?

Are the costs of building the project included? What is the percentage on it?

Is the project receiving subsidies from the government? What is the percentage on it?

Is the project receiving extra development rights from the government? What is the percentage on it?

Are the landowners receiving serviced land, development rights or payment at the end of the process?

Are the landowners getting all the benefits they are entitled to?

Are they selling land or rights to cover the development of the infrastructure and services?

Are they selling land or rights to cover the development of the project?

\section{Land value sharing} in an equitable distribution of cost and benefits. what is the average time for projects?

(1) list of the cost recovery tools and their efficiency. (2) what is the max, average and minimum cost recovery in the projects (\%)?

The construction process and the costs are included in Ir process $(y / n)$.

List of the subsidies that can be used in Ir.

(1) list of the value captures tools, (2) what is the max, average and minimum value capture in the projects (\%)?

(1) list of the distribution bases in Ir projects. (2) what are the criteria used in the selection of the distribution base? (3) the differences in allocation is calculated and compensated $(\mathrm{y} / \mathrm{n})$. If yes; how is the process?

Mobilizing the increments on the value of land created by the different stakeholders to benefit the community as a hole and the stakeholders

\begin{tabular}{l|l|l}
\hline Mobilizing & $\begin{array}{l}\text { Is the value being mobilized or payed out by some } \\
\text { stakeholders? }\end{array}$ & $\begin{array}{l}\text { List of the existing criteria for the allocation. } \\
\text { How is the allocation process? }\end{array}$ \\
\hline $\begin{array}{l}\text { Is the increase in the value of land being distributed } \\
\text { equitably amongst stakeholders? Percentage of value } \\
\text { perceived by each stakeholder? }\end{array}$ & $\begin{array}{l}\text { (1) list of the cost payers. (2) what is the max, } \\
\text { average and min percentage of the costs paid } \\
\text { by each actor? }\end{array}$ \\
\hline $\begin{array}{ll}\text { Equitable distribution } \\
\text { "is there any assessment process for equality of } \\
\text { landowners, how is the sharing of the costs and the } \\
\text { profits?" }\end{array}$ & $\begin{array}{l}\text { (1) is there any assessment process for equality } \\
\text { of landowners, (2) how is the sharing of the } \\
\text { costs and the profits? }\end{array}$ \\
\hline
\end{tabular}




\begin{tabular}{|c|c|c|c|}
\hline Variables & Indicators & Method & Instruments \\
\hline \multicolumn{4}{|c|}{ Voluntary participation of landowners } \\
\hline \multicolumn{4}{|c|}{$\begin{array}{l}\text { Participation of landowners is a direct inclusion of original owners in the decision-making process of land readjustment projects. Without } \\
\text { buying out landowners. And is fundamental for the implementation of a Ir project. }\end{array}$} \\
\hline \multirow{9}{*}{ Direct inclusion } & \multirow{2}{*}{$\begin{array}{l}\text { Are the landowners participating in the decision-making } \\
\text { process? }(y / n)\end{array}$} & Qualitative & Interviews \\
\hline & & Qualitative & Experts interviews \\
\hline & Percentage of landowners participating & Quantitative & Document survey \\
\hline & What it is the decision-making process like? & Qualitative & Interviews \\
\hline & $\begin{array}{l}\text { "the Ir projects are explained in details to the landowners. } \\
(y / n) \text { " }\end{array}$ & Qualitative & Interviews \\
\hline & Number of meetings hold with landowners & Qualitative & Interviews \\
\hline & Kind of decisions taken by the landowners & Qualitative & Interviews \\
\hline & \multirow{2}{*}{$\begin{array}{l}\text { "it is possible for land ownership disputes to cause delays } \\
\text { in projects? }(y / n) "\end{array}$} & Qualitative & Interviews \\
\hline & & Qualitative & Experts interviews \\
\hline \multirow{4}{*}{ Original landowners } & $\begin{array}{l}\text { Is the property registry reflecting expropriation or } \\
\text { compulsory acquisition before the project? }(y / n)\end{array}$ & Quantitative & Cadaster data \\
\hline & Is the government a landowner? $(y / n)$ & Quantitative & Document survey \\
\hline & $\begin{array}{l}\text { Is there any "measure for landowners to remain after the } \\
\text { project? }(y / n) \text { " }\end{array}$ & Qualitative & Interviews \\
\hline & $\begin{array}{l}\text { Where there transparency issues in the land registration } \\
\text { history? }(y / n)\end{array}$ & Qualitative & Cadaster data \\
\hline \multirow{2}{*}{ No buying out } & $\begin{array}{l}\text { "is there any measure to reduce or prevent plot } \\
\text { speculation? }(y / n) \text {. If yes, list of the available measures" }\end{array}$ & Qualitative & Interviews \\
\hline & $\begin{array}{l}\text { "is there any solution for landowners who want to leave } \\
\text { the project? }(y / n) \text { if yes, list them." }\end{array}$ & Qualitative & Interviews \\
\hline \multicolumn{4}{|c|}{ Cost recovery tool } \\
\hline \multicolumn{4}{|c|}{$\begin{array}{l}\text { Cost recovery is the process of self-financing a land readjustment by valuating the initial plots of land and calculating the future value afte } \\
\text { the project, the difference should be used to reserve part of the land for allocation of services and infrastructure needed for the project, } \\
\text { selling part of the land to pay for the installation of those services and the infrastructure and giving back to landowners the appreciated } \\
\text { residual land distributed by the same proportion they contributed. }\end{array}$} \\
\hline \multirow{4}{*}{ Valuation } & \multirow{2}{*}{$\begin{array}{l}\text { Is the project calculating the initial value of land? What is } \\
\text { the percentage on it? }\end{array}$} & Quantitative & Document survey \\
\hline & & Qualitative & Interviews \\
\hline & \multirow{2}{*}{$\begin{array}{l}\text { Is the project calculating the final value of land? What is } \\
\text { the percentage on it? }\end{array}$} & Quantitative & Document survey \\
\hline & & Qualitative & Interviews \\
\hline
\end{tabular}


Cost recovery tool

\begin{tabular}{|c|c|c|c|}
\hline & & Quantitative & Document survey \\
\hline & so & Qualitative & Interviews \\
\hline & & Quantitative & Document survey \\
\hline & 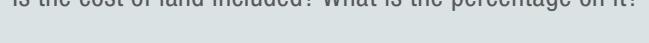 & Qualitative & Interviews \\
\hline & Is the cost of land reserved for public use included? What & Quantitative & Document survey \\
\hline & is the percentage on it? & Qualitative & Interviews \\
\hline & & Quantitative & Document survey \\
\hline & $\begin{array}{l}\text { Is the cost of in-site services and infrastructure included? } \\
\text { What is the percentage on it? }\end{array}$ & Qualitative & Interviews \\
\hline & & Quantitative & Sectorial publications \\
\hline & & Quantitative & Document survey \\
\hline 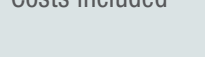 & $\begin{array}{l}\text { Is the cost of off-site services and infrastructure included? } \\
\text { What is the percentage on it? }\end{array}$ & Qualitative & Interviews \\
\hline & & Quantitative & Sectorial publications \\
\hline & & Quantitative & Document survey \\
\hline & 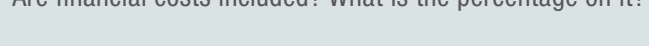 & Qualitative & Interviews \\
\hline & & Quantitative & Document survey \\
\hline & $\begin{array}{l}\text { Are profits included as costs? What is the percentage on } \\
\text { it? }\end{array}$ & Qualitative & Interviews \\
\hline & & Qualitative & Experts interviews \\
\hline & & Quantitative & Document survey \\
\hline & $\begin{array}{l}\text { Are the costs of building the project included? What is the } \\
\text { percentage on it? }\end{array}$ & Qualitative & Interviews \\
\hline & & Quantitative & Sectorial publications \\
\hline & Is the project receiving subsidies from the government? & Quantitative & Document survey \\
\hline & What is the percentage on it? & Qualitative & Interviews \\
\hline & Is the project receiving extra development rights from the & Quantitative & Document survey \\
\hline & government? What is the percentage on it? & Qualitative & Interviews \\
\hline & $\begin{array}{l}\text { Are the landowners receiving serviced land, development } \\
\text { rights or payment at the end of the process? }\end{array}$ & Qualitative & Interviews \\
\hline & $\begin{array}{l}\text { Are the landowners getting all the benefits they are } \\
\text { entitled to? }\end{array}$ & Qualitative & Interviews \\
\hline & $\begin{array}{l}\text { Are they selling land or rights to cover the development of } \\
\text { the infrastructure and services? }\end{array}$ & Qualitative & Interviews \\
\hline & $\begin{array}{l}\text { Are they selling land or rights to cover the development of } \\
\text { the project? }\end{array}$ & Qualitative & Interviews \\
\hline
\end{tabular}




\section{Land value sharing}

Mobilizing the increments on the value of land created by the different stakeholders to benefit the community as a hole and the stakeholders in an equitable distribution of cost and benefits.

\begin{tabular}{|l|l|l|l|}
\hline Mobilizing & $\begin{array}{l}\text { Is the value being mobilized or payed out by some } \\
\text { stakeholders? }\end{array}$ & Qualitative & Interviews \\
\hline $\begin{array}{l}\text { Is the increase in the value of land being distributed } \\
\text { equitably amongst stakeholders? Percentage of value } \\
\text { perceived by each stakeholder? }\end{array}$ & Quantitative & Document survey \\
\hline Equitable distribution & $\begin{array}{l}\text { "is there any assessment process for equality of } \\
\text { landowners, how is the sharing of the costs and the } \\
\text { profits?" }\end{array}$ & Qualitative & Interviews \\
\hline
\end{tabular}

\section{Anexo 2. Data Assumptions}

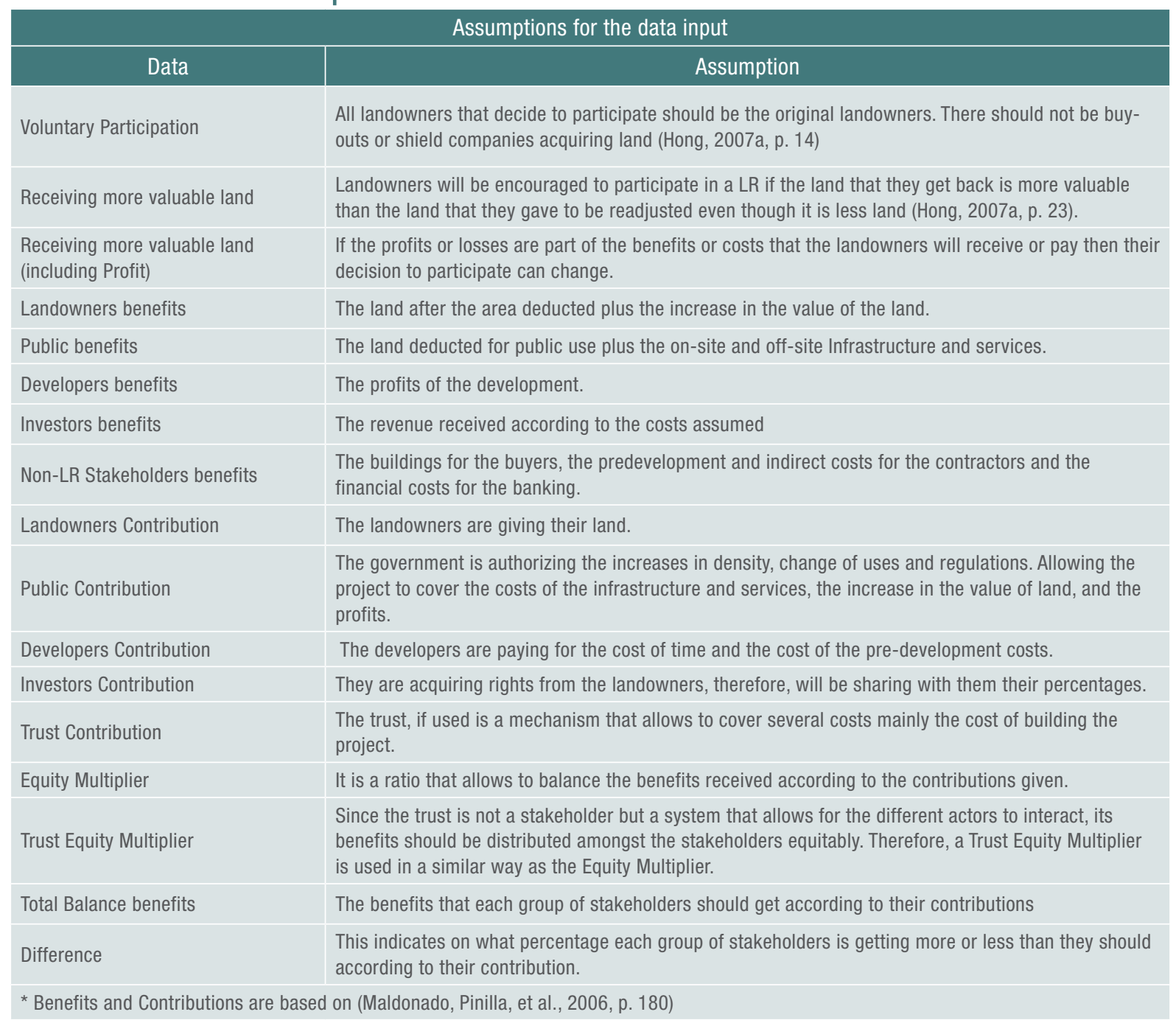




\section{Anexo 3. Data Template-Code Book}

\section{a. Data Assumptions}

\begin{tabular}{|c|c|c|c|c|}
\hline \multicolumn{5}{|c|}{ Assumptions for the data input } \\
\hline \multicolumn{5}{|c|}{ Rules for all the cells: } \\
\hline 1 & \multicolumn{4}{|c|}{$\begin{array}{l}\text { All the information included in any of the sheets should be obtained from the decree enacting each PP or in the Technical } \\
\text { Support Document (Documento técnico de Soporte - DTS) and it should be highlighted in the document to make it easy for } \\
\text { the reader to trace the reference or the assumptions. }\end{array}$} \\
\hline 2 * & \multicolumn{4}{|c|}{$\begin{array}{l}\text { Any remark or annotation can be made at the bottom of each sheet by adding consecutive asterisks to number them and } \\
\text { also include the asterisks in the cell to be clarified. Notes area can also be used to include additional information of the PP or } \\
\text { the UAU - UG that can help illustrate the case, for example the areas of the others UAU -UG can help understand the size of } \\
\text { the project. }\end{array}$} \\
\hline 3 & \multicolumn{4}{|c|}{ All the cells in light green should be fill in. } \\
\hline 4 & \multicolumn{4}{|c|}{$\begin{array}{l}\text { If a formula is changed because it will reflect the situation of the particular project this should be highlighted in orange and } \\
\text { explain in the notes at the bottom of the sheet. }\end{array}$} \\
\hline 5 & \multicolumn{4}{|c|}{ Yellow highlights are used for important information or results that will be useful to answer the research questions. } \\
\hline 6 & \multicolumn{4}{|c|}{$\begin{array}{l}\text { The formulas in the comments column of this sheet are indicative, the may change if more columns or rows are inserted in } \\
\text { the spreadsheets. }\end{array}$} \\
\hline \multicolumn{5}{|c|}{ * this format is based on the document Morales2015e_LandValueFinancialAnalysis.xls by Carlos Morales-Schechinger (2015) } \\
\hline Sheet & Concept & Cell & Explanation & Comments \\
\hline \multirow{7}{*}{ Participation } & $\begin{array}{l}\text { Management Unit } \\
\text { - Urban Action Unit } \\
\text { (UAU) - \# }\end{array}$ & A1 & $\begin{array}{l}\text { The Urban Action Unit (UAU) is the mechanism } \\
\text { us in the Colombian law } 388 \text { of } 1997 \text { to } \\
\text { develop a defined area of a Partial Plan (PP) } \\
\text { using any of the variants of Land Readjustment } \\
\text { (LR). Management Unit (Unidad de Gestión - } \\
\text { UG) is a common practice in the country to } \\
\text { recognize the development of an area but with } \\
\text { the agreement of all landowners, this practice } \\
\text { is not state in the law. }\end{array}$ & $\begin{array}{l}\text { In this cell the number of the } \\
\text { UAU - UG should be fill in, if } \\
\text { there is only one UAU - UG then it } \\
\text { should be completed by the word } \\
\text { "single". }\end{array}$ \\
\hline & Owner & A3.... & $\begin{array}{l}\text { Are the names of each landowner as it is } \\
\text { stated in the decree or in the Technical Support } \\
\text { Document (Documento técnico de Soporte - } \\
\text { DTS) }\end{array}$ & $\begin{array}{l}\text { This information can be } \\
\text { triangulated with the certificate } \\
\text { of tradition of the property }\end{array}$ \\
\hline & Area & B3.... & $\begin{array}{l}\text { Is the area of each plot or group of plots owned } \\
\text { by the same landowner as it is stated in the } \\
\text { decree or in the Technical Support Document } \\
\text { (Documento técnico de Soporte - DTS) }\end{array}$ & $\begin{array}{l}\text { If a landowner owns more than } \\
\text { one plot the area should be } \\
\text { added in one single row }\end{array}$ \\
\hline & \# of plots & C3.... & $\begin{array}{l}\text { Is the number of plots owned by each } \\
\text { landowner that the area in column B is } \\
\text { representing }\end{array}$ & $\begin{array}{l}\text { Regardless of the area of each } \\
\text { plot. }\end{array}$ \\
\hline & $\%$ of ownership & D3.... & $\begin{array}{l}\text { Is the percentage of land owned by each } \\
\text { landowner from the total area of the UAU - UG }\end{array}$ & Formula $=\mathrm{B} 3 * 1 / \mathrm{B} \$ 5$ \\
\hline & Participating & E3.... & $\begin{array}{l}\text { The will of a landowner to participate may } \\
\text { change during time or even the owner may } \\
\text { change, to fill in this cells the researcher } \\
\text { should find in the texts evidence of the } \\
\text { willingness to participate of each owner, this } \\
\text { information will be find easily in the DTS } \\
\text { as it might explain deeper than the decree. } \\
\text { In Colombia Participation is calculated as a } \\
\text { percentage of the area involved in the LR, as } \\
\text { explain by Maldonado, Pinilla, et al. (2006) }\end{array}$ & $\begin{array}{l}\text { Fill in with values } 1=\text { participating, } \\
0=\text { NOT participating }\end{array}$ \\
\hline & $\%$ of Participation & F3.... & $\begin{array}{l}\text { If each landowner is agree in this column } \\
\text { should appear the same percentage as in } \\
\text { column D }\end{array}$ & Formula $=\mathrm{IF}(\mathrm{E} 3=1 ; \mathrm{D} 3 ; 0)$ \\
\hline
\end{tabular}




\begin{tabular}{|c|c|c|c|c|}
\hline \multirow[t]{4}{*}{ Participation } & Original Landowner & G3.... & $\begin{array}{l}\text { In some cases there can be found evidence of } \\
\text { buying out of landowners, for example when } \\
\text { a real state company or a trust is created } \\
\text { and buys land previous to the enactment of } \\
\text { the decree they should appear as owners } \\
\text { of several plots o land, since this practice } \\
\text { is perfectly legal it does not constitute a } \\
\text { misconduct and proofs can be found in } \\
\text { the documents stating clearly that those } \\
\text { companies bought that land. But since this } \\
\text { is a critical point according to theory of the } \\
\text { LR process the fact that they are buying out } \\
\text { landowners constitutes a misapplication of the } \\
\text { instrument. }\end{array}$ & $\begin{array}{l}\text { Fill in with values } 1=\text { Voluntary } \\
\text { participating, } 0=\text { NOT voluntary } \\
\text { participating }\end{array}$ \\
\hline & $\begin{array}{l}\text { Voluntary } \\
\text { Participation }\end{array}$ & H3.... & $\begin{array}{l}\text { If each landowner is the original landowner } \\
\text { and is voluntarily participating in the LR in this } \\
\text { column should appear the same percentage as } \\
\text { in column F }\end{array}$ & Formula $=\mathrm{IF}(\mathrm{G} 3=1 ; \mathrm{F} 3 ; 0)$ \\
\hline & Totals & & $\begin{array}{l}\text { Aggregates the values of each column, the } \\
\text { total values of column } \mathrm{F} \text { and } \mathrm{H} \text { are used in the } \\
\text { summary as an input to answer main questions }\end{array}$ & Formula =SUM(B3:B4) \\
\hline & notes & & $\begin{array}{l}\text { this area should be used to explain specific } \\
\text { cells information. }\end{array}$ & \\
\hline \multirow{8}{*}{$\begin{array}{l}\text { Land Value } \\
\text { Capture - LVC }\end{array}$} & Value PP & B4-B6 & $\begin{array}{l}\text { If the PP has different UAU's then it could be } \\
\text { important to have a comparison and context for } \\
\text { this values. }\end{array}$ & \\
\hline & Value UAU-\# & C3 & $\begin{array}{l}\text { In this cell the number of the UAU - UG should } \\
\text { be fill in, if there is only one UAU - UG then it } \\
\text { should be completed by the word "single". }\end{array}$ & \\
\hline & Initial Value of Land & C4 & $\begin{array}{l}\text { Is the value of all the plots of land in the UAU - } \\
\text { UG with the initial conditions of development, } \\
\text { as it is stated in the decree or in the Technical } \\
\text { Support Document (Documento técnico de } \\
\text { Soporte - DTS) }\end{array}$ & $\begin{array}{l}\text { normally this value is shared by } \\
\text { the developer as the appraisal } \\
\text { is done. }\end{array}$ \\
\hline & Final Value of Land & C5 & $\begin{array}{l}\text { Is the value of all the plots of land in the } \\
\text { UAU - UG after de project is finished, as it is } \\
\text { stated in the decree or in the Technical Support } \\
\text { Document (Documento técnico de Soporte - } \\
\text { DTS) }\end{array}$ & $\begin{array}{l}\text { normally this value is shared by } \\
\text { the developer with a calculation } \\
\text { of the residual value of land }\end{array}$ \\
\hline & $\begin{array}{l}\text { Increment in the } \\
\text { Value of Land }\end{array}$ & C6 & $\begin{array}{l}\text { Is the percentage that land has appreciated } \\
\text { according to the values stated in the decree or } \\
\text { in the Technical Support Document (Documento } \\
\text { técnico de Soporte - DTS) }\end{array}$ & Formula $=(\mathrm{C} 5-\mathrm{C} 4) / \mathrm{C} 4$ \\
\hline & $\begin{array}{l}\text { Total Area (Gross } \\
\text { area) }\end{array}$ & B9 & $\begin{array}{l}\text { Is the total area of the plots included in the } \\
\text { UAU - UG. }\end{array}$ & Formula =Participation. B5 \\
\hline & Initial Value/m2 & C9 & $\begin{array}{l}\text { Is the value per square meter of land in } \\
\text { the UAU - UG with the initial conditions of } \\
\text { development, calculated as the quotient of the } \\
\text { initial value of land divided by the area of the } \\
\text { UAU - UG. }\end{array}$ & Formula $=$ C4/B9 \\
\hline & Final Value/m2 & D9 & $\begin{array}{l}\text { Is the value per square meter of land in } \\
\text { the UAU - UG after de project is finished, } \\
\text { calculated as the quotient of the Final value of } \\
\text { land divided by the area of the UAU - UG. }\end{array}$ & Formula $=$ C5/B9 \\
\hline
\end{tabular}


Is the percentage that land has appreciated

Increment

E9

Residual Area (Net area)

Area of Public streets

Residual Area (Net area)

$\%$ of Adjusted area

Final Value of Adjusted Land

Receiving more
valuable land?
calculated from the initial and final value of the land per square meter.

the area that all of the landowners will get back to develop after the readjustment is done is deducted from the gross area of land.

Is the area deducted for public streets as it is stated in the decree or in the Technical Support Document (Documento técnico de Soporte DTS), this category can be adjusted to better reflect the conditions of the project.

Is the area deducted for public green spaces as it is stated in the decree or in the Technical Support Document (Documento técnico de Soporte - DTS), this category can be adjusted to better reflect the conditions of the project.

Is the area deducted for public infrastructure as it is stated in the decree or in the Technical Support Document (Documento técnico de Soporte - DTS), this category can be adjusted to better reflect the conditions of the project.

Is the sum of all the areas taken for public use

Is the difference resulting from subtracting the total area for public use from the gross area.

Formula $=(D 9-C 9)^{\star} 1 / C 9$

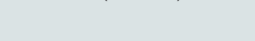

If the category is adjusted change the name in cell A13, try NOT to include new rows between row 12 and row 16 to keep the number of cells fixed.

If the category is adjusted change the name in cell A14, try NOT to include new rows between row 12 and row 16 to keep the number of cells fixed.

Formula $=\operatorname{SUM}(B 12: B 14)$

Formula $=$ B9-B15

According to theory this area can be sold to pay for the costs of developing the project and the benefits be obtained as a payment instead of in kind, this is refer to the "adjustment" in theory

is the area of land that all of the landowners will bet back after the readjustment express as a percentage of the total area.

Is the total amount of cash that the landowners will receive if they sell the adjusted land at the appreciated value calculated with the residual value of land.

According to theory landowners will be encouraged to participate in a LR if the the land that they get back is more valuable than the land that they gave to be readjusted even though it is less land.

Is the area that all of the landowners will get back to develop after the readjustment is done

Is the value per square meter of land in the UAU - UG after de project is finished, including the profits, calculated as the quotient of the Final value of land plus the profits divided by the residual area or adjusted area.
Formula $=B 19^{*} 1 / B 9$

Formula $=B 19^{\star} \mathrm{D} 9$

Formula

=IF(D19>=C4;"YES";"NO")

According to theory all the profits or losses should be obtained or covered by the landowners, therefore any profit or loss should be added to or deducted from the final value of land so the landowners will benefit or bare this value.

Formula ='Summary ‘.19/B9 


\begin{tabular}{|c|c|c|c|c|}
\hline Sheet & Concept & Cell & Explanation & Comments \\
\hline \multirow{3}{*}{$\begin{array}{l}\text { Land Value } \\
\text { Capture - LVC }\end{array}$} & $\begin{array}{l}\text { Final Value of } \\
\text { Adjusted Land }+ \\
\text { Profits }\end{array}$ & D23 & $\begin{array}{l}\text { Is the total amount of cash that the landowners } \\
\text { will receive if they sell the adjusted land at } \\
\text { the appreciated value including the profits, } \\
\text { calculated as a product of the final value of } \\
\text { land per square meter including profits by the } \\
\text { adjusted area or net area. }\end{array}$ & Formula $=\mathrm{B} 23^{*} \mathrm{C} 23$ \\
\hline & $\begin{array}{l}\text { Receiving more } \\
\text { valuable land? }\end{array}$ & E23 & $\begin{array}{l}\text { According to theory landowners will be } \\
\text { encouraged to participate in a LR if the the } \\
\text { land that they get back is more valuable } \\
\text { than the land that they gave to be readjusted } \\
\text { even though it is less land. If the profits or } \\
\text { losses are part of the benefits or costs that } \\
\text { the landowners will receive or pay then their } \\
\text { decision to participate can change. }\end{array}$ & $\begin{array}{l}\text { Formula } \\
=\mathrm{IF}(\mathrm{D} 23>=\mathrm{C} 4 ; " Y E S " ; " N 0 ")\end{array}$ \\
\hline & notes & & $\begin{array}{l}\text { this area should be used to explain specific } \\
\text { cells information. }\end{array}$ & \\
\hline \multirow{11}{*}{$\begin{array}{l}\text { Cost-Benefit } \\
\text { Analysis }\end{array}$} & Unit & B1 & $\begin{array}{l}\text { Is the unit of calculation for the listed costs or } \\
\text { benefits. }\end{array}$ & $\begin{array}{l}\text { Square meters }=\text { M2, Percentage } \\
=\%, \text { Global unit }=\mathrm{GL}\end{array}$ \\
\hline & Quantity & C1 & Is the amount of the item to be calculated & \\
\hline & Unit value & D1 & is the cost of one unit of the item calculated & \\
\hline & Calculated Value & E1 & $\begin{array}{l}\text { Is the result of multiplying the quantity by the } \\
\text { unit value. The Calculated Value is used here to } \\
\text { verify if the information listed in the documents } \\
\text { coincides with the mathematical calculation } \\
\text { of it }\end{array}$ & Formula $=\mathrm{C} 3^{*} \mathrm{D} 3$ \\
\hline & Listed value & $\mathrm{F} 1$ & $\begin{array}{l}\text { Is the cost used for each item as it is stated } \\
\text { in the decree or in the Technical Support } \\
\text { Document (Documento técnico de Soporte - } \\
\text { DTS), this is the value that will be used for the } \\
\text { summary calculations. }\end{array}$ & $\begin{array}{l}\text { this value can variate from the } \\
\text { calculated values for several } \\
\text { reasons, some reasons are: } \\
\text { because of the model was a } \\
\text { dynamic model and it needs to } \\
\text { be presented as a static model, } \\
\text { because there are multipliers or } \\
\text { rates not show in the documents } \\
\text { like taxes, miscalculations or } \\
\text { others. }\end{array}$ \\
\hline & Percent Deviation & G1 & $\begin{array}{l}\text { Is the percentage of variation between the } \\
\text { calculated value and the listed value, it } \\
\text { can give an idea of the validity of the data } \\
\text { collected. }\end{array}$ & $\begin{array}{l}\text { Formula }=I F(A N D(E 7 ; F 7)<>0 \\
\left.(F 7-E 7)^{*} 1 / E 7 ; " N / A "\right)\end{array}$ \\
\hline & Costs & A2 & $\begin{array}{l}\text { Is the total amount of value that will be needed } \\
\text { to develop the UAU - UG. }\end{array}$ & \\
\hline & Cost of Land & A3 & $\begin{array}{l}\text { Is the cost of land deducting the cost of land } \\
\text { reserved for public use (Net Area). }\end{array}$ & \\
\hline & $\begin{array}{l}\text { Cost of land } \\
\text { reserved for public } \\
\text { use }\end{array}$ & A4 & $\begin{array}{l}\text { Is the cost of land reserved for public use (Total } \\
\text { Area Deducted). }\end{array}$ & \\
\hline & $\begin{array}{l}\text { Increase in the } \\
\text { value of land payed } \\
\text { to the landowners }\end{array}$ & A5 & $\begin{array}{l}\text { Is the value that land has appreciated } \\
\text { calculated as a residual from the final value of } \\
\text { the land minus the initial value of land. }\end{array}$ & \\
\hline & $\begin{array}{l}\text { Cost of in-site } \\
\text { services and } \\
\text { infrastructure }\end{array}$ & A6 & $\begin{array}{l}\text { Are the costs that the project has to cover } \\
\text { inside the area of the project in order to } \\
\text { fulfil the needs of the project. Called "Cargas } \\
\text { Locales" in Colombia. }\end{array}$ & \\
\hline
\end{tabular}


In-site 1

In-site 2

In-site $3 .$.

Cost of off-site

services and

infrastructure

Off-site 1

Off-site 2

Off-site $3 .$.

Financial costs

Cost-Benefit Analysis

Profits

Costs of building

the project

Indirect Costs of

building the project

Pre-development

Costs

Benefits

Subsidies from the government

Development rights received

Use 1 list the items as presented in the decree or in the Technical Support Document (Documento técnico de Soporte - DTS),

list the items as presented in the decree or in the Technical Support Document (Documento técnico de Soporte - DTS),

list the items as presented in the decree or in the Technical Support Document (Documento técnico de Soporte - DTS),

Are the costs that the project has to cover outside the area of the project in order to fulfil the needs of the project. Called "Cargas Generales" in Colombia.

list the items as presented in the decree or in the Technical Support Document (Documento técnico de Soporte - DTS),

list the items as presented in the decree or in the Technical Support Document (Documento técnico de Soporte - DTS),

list the items as presented in the decree or in the Technical Support Document (Documento técnico de Soporte - DTS),

Are the costs of the financing the project, including interest rates on borrowed cash.

Some projects include a cost of developing the project.

Are the costs associated with building the project, excluding the costs of infrastructure or services included in other items.

Are the costs that are not directly applied to the construction but that will allow for the project to be developed, like the contractors payment or the required studies.

Are the costs that the project has to pay before it starts its development.

Is the total amount of value that will receive the project to cover the costs and break even.

Are the benefits received from the government that is not linked to a sale of rights or area in the project.

Are the benefits in terms of Floor-Area Ratio (FAR) received to finance the project.

list the items as presented in the decree or in the Technical Support Document (Documento técnico de Soporte - DTS),
Can include the costs of developing the PP.

More rows can be included as needed.

More rows can be included as needed.

According to theory all the profits or losses should be obtained or covered by the landowners, therefore any profit or loss should be added to or deducted from the final value of land so the landowners will benefit or bare this value.

this benefits can be development rights, change of uses or incorporation of rural areas to urban uses. 


\begin{tabular}{|c|c|c|c|c|}
\hline \multirow{3}{*}{$\begin{array}{l}\text { Cost-Benefit } \\
\text { Analysis }\end{array}$} & Use 2 & & $\begin{array}{l}\text { list the items as presented in the decree or in } \\
\text { the Technical Support Document (Documento } \\
\text { técnico de Soporte-DTS), }\end{array}$ & \\
\hline & Use $3 \ldots$ & & $\begin{array}{l}\text { list the items as presented in the decree or in } \\
\text { the Technical Support Document (Documento } \\
\text { técnico de Soporte-DTS), }\end{array}$ & \\
\hline & notes & & $\begin{array}{l}\text { this area should be used to explain specific } \\
\text { cells information. }\end{array}$ & \\
\hline \multirow{12}{*}{ Summary } & \multicolumn{2}{|l|}{ Participation } & & \\
\hline & $\begin{array}{l}\text { percentage of } \\
\text { landowners } \\
\text { participating }\end{array}$ & C3 & $\begin{array}{l}\text { Is the total ratio of landowners participating in } \\
\text { the UAU - UG. }\end{array}$ & Formula $=\$$ Participation.F5 \\
\hline & $\begin{array}{l}\text { Percentage of Local } \\
\text { Government owned } \\
\text { land }\end{array}$ & C4 & $\begin{array}{l}\text { Is the total ratio of land owned by the } \\
\text { government participating in the UAU - UG. }\end{array}$ & $\begin{array}{l}\text { Fill in with the total percentage } \\
\text { of government owned land } \\
\text { participating in the UAU - UG. }\end{array}$ \\
\hline & $\begin{array}{l}\text { Original } \\
\text { Landowners }\end{array}$ & C5 & $\begin{array}{l}\text { Is the total ratio of landowners participating } \\
\text { Voluntarily in the UAU - UG. }\end{array}$ & Formula $=\$$ Participation. $\mathrm{H} 5$ \\
\hline & $\begin{array}{l}\text { Voluntary } \\
\text { Participation }\end{array}$ & C6 & $\begin{array}{l}\text { According to theory if the landowners } \\
\text { participating in the UAU - UG are voluntarily } \\
\text { joining without being bought out then it is a LR } \\
\text { in terms of the land assembly method used. } \\
\text { Therefore if the values of C3 and C5 are equal } \\
\text { this cell will be display the word YES. }\end{array}$ & Formula =IF(C5=C3;"YES";"NO") \\
\hline & \multicolumn{2}{|l|}{ LVC } & & \\
\hline & initial value of land & C8 & $\begin{array}{l}\text { Is the value of all the plots of land in the UAU - } \\
\text { UG with the initial conditions of development, } \\
\text { as it is stated in the decree or in the Technical } \\
\text { Support Document (Documento técnico de } \\
\text { Soporte - DTS) }\end{array}$ & Formula $=\$$ LVC.C4 \\
\hline & final value of land & C9 & $\begin{array}{l}\text { Is the value of all the plots of land in the } \\
\text { UAU - UG after de project is finished, as it is } \\
\text { stated in the decree or in the Technical Support } \\
\text { Document (Documento técnico de Soporte - } \\
\text { DTS) }\end{array}$ & Formula $=\$$ LVC.C5 \\
\hline & $\begin{array}{l}\text { Increment in the } \\
\text { Value of Land }\end{array}$ & C10 & $\begin{array}{l}\text { Is the percentage that land has appreciated } \\
\text { according to the values stated in the decree or } \\
\text { in the Technical Support Document (Documento } \\
\text { técnico de Soporte - DTS) }\end{array}$ & Formula $=(\mathrm{C} 9-\mathrm{C} 8)^{\star} 1 / \mathrm{C} 8$ \\
\hline & $\begin{array}{l}\text { Value of land } \\
\text { Including Profits }\end{array}$ & C11 & $\begin{array}{l}\text { Is the value of all the plots of land in the UAU } \\
\text { - UG after de project is finished, including the } \\
\text { profits. }\end{array}$ & $\begin{array}{l}\text { Formula }=C 9+\$ \text { 'Cost-Benefit } \\
\text { Analysis '.F15 }\end{array}$ \\
\hline & $\begin{array}{l}\text { Increment in the } \\
\text { Value of Land } \\
\text { including profits }\end{array}$ & C12 & $\begin{array}{l}\text { Is the percentage that land will appreciate if } \\
\text { the final value of land was calculated including } \\
\text { the profits. }\end{array}$ & Formula $=(\mathrm{C} 11-\mathrm{C} 8)^{*} 1 / \mathrm{C} 8$ \\
\hline & $\begin{array}{l}\text { Value of Land } \\
\text { without sharing } \\
\text { costs }\end{array}$ & C13 & $\begin{array}{l}\text { Is the value of all the plots of land in the UAU } \\
\text { - UG after de project is finished, if the final } \\
\text { value of land was calculated without sharing } \\
\text { the costs of building the infrastructure and } \\
\text { services required and including the profits. }\end{array}$ & $\begin{array}{l}\text { Formula }=\$ \text { 'Cost-Benefit Analysis } \\
\text { '.F3+\$'Cost-Benefit Analysis } \\
\text { '.F4+\$'Cost-Benefit Analysis } \\
\text { '.F5+\$'Cost-Benefit Analysis } \\
\text { '.F6+\$'Cost-Benefit Analysis } \\
\text { '.F10+\$'Cost-Benefit Analysis } \\
\text { '.F15 }\end{array}$ \\
\hline
\end{tabular}




\begin{tabular}{|c|c|c|c|c|}
\hline Sheet & Concept & Cell & Explanation & Comments \\
\hline \multirow{16}{*}{ Summary } & $\begin{array}{l}\text { Increment in the } \\
\text { Value of Land } \\
\text { without sharing } \\
\text { costs }\end{array}$ & C14 & $\begin{array}{l}\text { Is the percentage that land will appreciate, if } \\
\text { the final value of land was calculated without } \\
\text { sharing the costs of building the infrastructure } \\
\text { and services required and including the profits. }\end{array}$ & Formula $=(\mathrm{C} 13-\mathrm{C} 8)^{*} 1 / \mathrm{C} 8$ \\
\hline & \multicolumn{2}{|l|}{ Costs } & & \\
\hline & Cost of Time & C16 & $\begin{array}{l}\text { Is the percentage from the total costs that has } \\
\text { the value of time. }\end{array}$ & \\
\hline & Cost of Land & C17 & $\begin{array}{l}\text { Is the percentage from the total costs that has } \\
\text { the value of land deducting the cost of land } \\
\text { reserved for public use (Net Area). }\end{array}$ & $\begin{array}{l}\text { Formula }=\$ \text { 'Cost-Benefit Analysis } \\
\text { '.F3/\$'Cost-Benefit Analysis '.F2 }\end{array}$ \\
\hline & $\begin{array}{l}\text { Cost of land } \\
\text { reserved for public } \\
\text { use }\end{array}$ & C18 & $\begin{array}{l}\text { Is the percentage from the total costs that has } \\
\text { the cost of land reserved for public use (Total } \\
\text { Area Deducted). }\end{array}$ & $\begin{array}{l}\text { Formula }=\$ \text { 'Cost-Benefit Analysis } \\
\text { '.F4/\$'Cost-Benefit Analysis '.F2 }\end{array}$ \\
\hline & $\begin{array}{l}\text { Increase in the } \\
\text { value of land payed } \\
\text { to the landowners }\end{array}$ & C19 & $\begin{array}{l}\text { Is the percentage from the total costs that has } \\
\text { the value that land has appreciated calculated } \\
\text { as a residual from the final value of the land } \\
\text { minus the initial value of land. }\end{array}$ & $\begin{array}{l}\text { Formula }=\$ \text { 'Cost-Benefit Analysis } \\
\text { '.F5/\$'Cost-Benefit Analysis '.F2 }\end{array}$ \\
\hline & $\begin{array}{l}\text { Cost of in-site } \\
\text { services and } \\
\text { infrastructure }\end{array}$ & $\mathrm{C} 20$ & $\begin{array}{l}\text { Is the percentage from the total costs that has } \\
\text { the costs that the project has to cover inside } \\
\text { the area of the project in order to fulfil the } \\
\text { needs of the project. Called "Cargas Locales" } \\
\text { in Colombia. }\end{array}$ & $\begin{array}{l}\text { Formula }=\$ \text { 'Cost-Benefit Analysis } \\
\text { '.F6/ } \$ \text { 'Cost-Benefit Analysis '.F2 }\end{array}$ \\
\hline & $\begin{array}{l}\text { Cost of off-site } \\
\text { services and } \\
\text { infrastructure }\end{array}$ & C21 & $\begin{array}{l}\text { Is the percentage from the total costs that has } \\
\text { the costs that the project has to cover outside } \\
\text { the area of the project in order to fulfil the } \\
\text { needs of the project. Called "Cargas Generales" } \\
\text { in Colombia. }\end{array}$ & $\begin{array}{l}\text { Formula }=\$ \text { 'Cost-Benefit Analysis } \\
\text { '.F10/\$'Cost-Benefit Analysis '.F2 }\end{array}$ \\
\hline & Financial costs & $\mathrm{C} 22$ & $\begin{array}{l}\text { Is the percentage from the total costs that has } \\
\text { the costs of the financing the project, including } \\
\text { interest rates on borrowed cash. }\end{array}$ & $\begin{array}{l}\text { Formula }=\$ \text { 'Cost-Benefit Analysis } \\
\text { '.F14/\$'Cost-Benefit Analysis '.F2 }\end{array}$ \\
\hline & Profits & $\mathrm{C} 23$ & $\begin{array}{l}\text { Is the percentage from the total costs that has } \\
\text { the profits of the project.. }\end{array}$ & $\begin{array}{l}\text { Formula }=\$ \text { 'Cost-Benefit Analysis } \\
\text { '.F15/\$'Cost-Benefit Analysis '.F2 }\end{array}$ \\
\hline & $\begin{array}{l}\text { Costs of building } \\
\text { the project }\end{array}$ & C24 & $\begin{array}{l}\text { Is the percentage from the total costs that has } \\
\text { the costs associated with building the project, } \\
\text { excluding the costs of infrastructure or services } \\
\text { included in other items. }\end{array}$ & $\begin{array}{l}\text { Formula }=\$ \text { 'Cost-Benefit Analysis } \\
\text { '.F16/\$'Cost-Benefit Analysis '.F2 }\end{array}$ \\
\hline & $\begin{array}{l}\text { Indirect Costs of } \\
\text { building the project }\end{array}$ & C25 & $\begin{array}{l}\text { Is the percentage from the total costs that has } \\
\text { the costs that are not directly applied to the } \\
\text { construction but that will allow for the project } \\
\text { to be developed, like the contractors payment } \\
\text { or the required studies. }\end{array}$ & $\begin{array}{l}\text { Formula }=\$ \text { 'Cost-Benefit Analysis } \\
\text { '.F17/ } \$ \text { 'Cost-Benefit Analysis '.F2 }\end{array}$ \\
\hline & $\begin{array}{l}\text { Pre-development } \\
\text { Costs }\end{array}$ & C26 & $\begin{array}{l}\text { Is the percentage from the total costs that has } \\
\text { the costs that the project has to pay before it } \\
\text { starts its development. }\end{array}$ & $\begin{array}{l}\text { Formula }=\$ \text { 'Cost-Benefit Analysis } \\
\text { '.F18/\$'Cost-Benefit Analysis '.F2 }\end{array}$ \\
\hline & \multicolumn{2}{|l|}{ Benefits } & & \\
\hline & $\begin{array}{l}\text { Subsidies from the } \\
\text { government }\end{array}$ & C28 & $\begin{array}{l}\text { Is the percentage from the total benefits that } \\
\text { has the benefits received from the government } \\
\text { that is not linked to a sale of rights or area in } \\
\text { the project. }\end{array}$ & $\begin{array}{l}\text { Formula }=\$ \text { 'Cost-Benefit Analysis } \\
\text { '.F20/\$'Cost-Benefit Analysis } \\
\text { 'F19 }\end{array}$ \\
\hline & Development rights & C29 & $\begin{array}{l}\text { Is the percentage from the total benefits that } \\
\text { has the benefits in terms of Floor-Area Ratio } \\
\text { (FAR) received to finance the project. }\end{array}$ & $\begin{array}{l}\text { Formula }=\$ ' \text { Cost-Benefit Analysis } \\
\text { 'F21/\$'Cost-Benefit Analysis } \\
\text { 'F19 }\end{array}$ \\
\hline
\end{tabular}


Value Sharing

Landowners
benefits

Public benefits

Developers benefits

Investors benefits

Trust benefits

Non LR

Stakeholders

(buyers, contractors or others)

\section{Non LR}

Stakeholders

(buyers or others)

Non LR

Summary
Stakeholders

(contractors)

Banking
Equity Multiplier

C41

Balanced benefits
According to theory every stakeholder should benefit according to what it has contributed. In this cells the contribution distribution should be expressed.

It is a ratio that allows to balance the benefits received according to the contributions given.

Are the percentages of benefits that each stakeholder should received according to it contributions.
Is the percentage of the benefits received by the landowners, according to theory this will be of the land.

Is the percentage of the benefits received by costs

Is the percentage of the benefits received by the developers, the profits.

the Investors.

Is the percentage of the benefits received by

Is the percentage of the benefits received by Is the percentage of the benefits received by other actors that are not stakeholders mostly related to buyers of the project. contractors.

Is the percentage of the benefits received by the financial sector.

$E 30-E 35$

Formula $=\mathrm{C} 17+\mathrm{C} 19$

Formula $=\mathrm{C} 18+\mathrm{C} 20+\mathrm{C} 21$

Formula $=\mathrm{C} 16+\mathrm{C} 23$

Formula $=\mathrm{C} 24$

Formula $=\mathrm{C} 25+\mathrm{C} 26$

Formula $=\mathrm{C} 22$

The standard formulas are in accordance with what theory explains about the contribution of each stakeholder: the landowners are giving their land: $=\mathrm{C} 17+\mathrm{C} 18$. The government is authorizing the increases in density, change of uses and regulations: $=\mathrm{C} 19+\mathrm{C} 20+\mathrm{C} 21+\mathrm{C} 23$. The developers are paying for the cost of time and the cost of the predevelopment costs: $=\mathrm{C} 16+\mathrm{C} 26$. The investors are acquiring rights from the landowners and therefore will be sharing with them their percentages. The trust, if used is a mechanism that allows to cover several costs mainly the cost of building the project: $=\mathrm{C} 22+\mathrm{C} 24+\mathrm{C} 25$.

Formula $=\mathrm{C} \$ 30 / \mathrm{SUM}(\mathrm{D} \$ 31: \mathrm{D} \$ 35)$

Formula $=\mathrm{D} 31^{\star} \mathrm{C} \$ 41$ 


\begin{tabular}{|c|c|c|c|c|}
\hline Sheet & Concept & Cell & Explanation & Comments \\
\hline \multirow{6}{*}{ Summary } & $\begin{array}{l}\text { Trust Equity } \\
\text { Multiplier }\end{array}$ & C42 & $\begin{array}{l}\text { Since the trust is not a stakeholder but a } \\
\text { system that allows for the different actors } \\
\text { to interact, its benefits should be distributed } \\
\text { amongst the stakeholders equitably. Therefore } \\
\text { a Trust Equity Multiplier is used in a similar } \\
\text { way as the Equity Multiplier. }\end{array}$ & Formula $=\mathrm{E} \$ 35 / \mathrm{SUM}(\mathrm{D} \$ 31: \mathrm{D} \$ 34)$ \\
\hline & trust benefits & $F 30-F 35$ & $\begin{array}{l}\text { This cells show the percentage of the trust } \\
\text { benefits that each group of stakeholders } \\
\text { should receive. }\end{array}$ & Formula $=\mathrm{D} 31^{*} \mathrm{C} \$ 42$ \\
\hline & $\begin{array}{l}\text { Total Balance } \\
\text { benefits }\end{array}$ & G30 - G35 & $\begin{array}{l}\text { This is the total percentage of the benefits } \\
\text { that each group of stakeholders should get } \\
\text { according to their contributions }\end{array}$ & Formula $=\mathrm{E} 31+\mathrm{F} 31$ \\
\hline & Difference & $\mathrm{H} 30-\mathrm{H} 35$ & $\begin{array}{l}\text { This indicates in what percentage each group } \\
\text { of stakeholders is getting more or less than } \\
\text { they should according to their contribution. }\end{array}$ & Formula $=\mathrm{C} 31-\mathrm{G} 31$ \\
\hline & Total & H36 & $\begin{array}{l}\text { This indicates the percentage above or below } \\
\text { the equitable distribution of the benefits each } \\
\text { project is. }\end{array}$ & Formula $=\mathrm{SUM}(\mathrm{H} 31: \mathrm{H} 34)$ \\
\hline & notes & & $\begin{array}{l}\text { this area should be used to explain specific } \\
\text { cells information. }\end{array}$ & \\
\hline
\end{tabular}

\section{b. Participation Sheet}

\begin{tabular}{|l|r|r|r|r|r|r|r|}
\hline \multicolumn{1}{|c|}{ Owner } & \multicolumn{1}{|c|}{ Management Unit - Urban Action Unit (UAU) - 2} \\
\hline Area & \# of plots & $\begin{array}{c}\text { \% of } \\
\text { ownership }\end{array}$ & Participating & $\begin{array}{c}\text { \% of } \\
\text { Participation }\end{array}$ & $\begin{array}{c}\text { Original } \\
\text { Landowner }\end{array}$ & $\begin{array}{c}\text { Voluntary } \\
\text { Participation }\end{array}$ \\
\hline Ciudadela El Rincón S.A. * & $115.828,00$ & 1 & $95,00 \%$ & 1 & $95,00 \%$ & 0 & $0,00 \%$ \\
\hline Municipio de Medellín & $6.096,00$ & 1 & $5,00 \%$ & 1 & $5,00 \%$ & 1 & $5,00 \%$ \\
\hline Total & $121.924,00$ & 2 & $100,00 \%$ & & $100,00 \%$ & $5,00 \%$ \\
\hline
\end{tabular}

\section{c. Land Value Capture Sheet}

\begin{tabular}{|l|r|r|}
\hline \multicolumn{1}{|c|}{ Item } & \multicolumn{1}{|c|}{ Value PP } & \multicolumn{1}{|c|}{ Value UAU-2 } \\
\hline Initial Value of Land & $\$ 18.415 .270,00$ & $\$ 7.934 .880,00$ \\
\hline Final Value of Land & $\$ 23.989 .404,00$ & $\$ 11.505 .536,00$ \\
\hline Increment in the Value of land & $30,27 \%$ & $45,00 \%$ \\
\hline
\end{tabular}

\begin{tabular}{|c|c|c|c|c|}
\hline Total Area (Gross area) & Area & Initial Value/m² & final Value $/ m^{2}$ & Increment \\
\hline UAU-2 & $121.924,00$ & $\$ 65,08$ & $\$ 94,37$ & $45,00 \%$ \\
\hline Residual Area (Net area) & Area & & & \\
\hline Area of Public strees & $22.738,00$ & & & \\
\hline Area of Public green spaces & $21.137,00$ & & & \\
\hline Area of Public infrastructure & $10.700,00$ & & & \\
\hline Total Area deducted & $54.575,00$ & & & \\
\hline Residual Area (Net area) & $67.349,00$ & & & \\
\hline
\end{tabular}




\begin{tabular}{|c|c|c|c|c|}
\hline \multicolumn{1}{|c|}{ Projected Adjusted area } & Area & \%of Adjusted area & $\begin{array}{c}\text { Final Value of } \\
\text { Adjusted Land }\end{array}$ & $\begin{array}{c}\text { Receiving more } \\
\text { valuable land? }\end{array}$ \\
\hline Projected Adjusted area** & $67.349,00$ & $55,24 \%$ & $\$ 6.355 .486,57$ & N0 \\
\hline Projected Adjusted area + Profits & Area & Final Value/m ${ }^{2}$ & $\begin{array}{c}\text { Final Value of } \\
\text { Adjusted Land } \\
\text { + Profits }\end{array}$ & $\begin{array}{c}\text { Receiving more } \\
\text { valuable land? }\end{array}$ \\
\hline Adjusted Area + Profits & $67.349,00$ & $\$ 186,95$ & $\$ 12.590 .924,94$ & YES \\
\hline
\end{tabular}

\section{d. Cost-Benefit Analysis Sheet}

\begin{tabular}{|c|c|c|c|c|c|c|}
\hline Item & Unit & Quantity & Unit value & $\begin{array}{l}\text { Calculated } \\
\text { Value }\end{array}$ & Listed value & $\begin{array}{l}\text { Percent } \\
\text { Deviation }\end{array}$ \\
\hline Costs & & & & $\$ 26.450 .539,59$ & $\$ 148.120 .484,00$ & \\
\hline Cost of Land & M2 & $67.349,00$ & $\$ 65,08$ & $\$ 4.383 .109,42$ & $\$ 4.383 .109,42$ & $0,00 \%$ \\
\hline Cost of land reserved for public use & M2 & $54.575,00$ & $\$ 65,08$ & $\$ 3.551 .770,58$ & $\$ 3.551 .770,58$ & $0,00 \%$ \\
\hline $\begin{array}{l}\text { Increase in the value of land payed to } \\
\text { the landowners }\end{array}$ & M2 & $121.924,00$ & $\$ 29,29$ & $\$ 3.570 .656,00$ & $\$ 3.570 .656,00$ & $0,00 \%$ \\
\hline $\begin{array}{l}\text { Cost of in-site services and } \\
\text { infrastructure* }\end{array}$ & GL & & & $\$ 3.658 .225,00$ & $\$ 3.658 .225,00$ & $0,00 \%$ \\
\hline Public streets & M2 & $22.738,00$ & $\$ 100,00$ & $\$ 2.273 .800,00$ & $\$ 0,00$ & $-100,00 \%$ \\
\hline Green areas & M2 & $21.137,00$ & $\$ 25,00$ & $\$ 528.425,00$ & $\$ 0,00$ & $-100,00 \%$ \\
\hline infrastructure & M2 & $10.700,00$ & $\$ 80,00$ & $\$ 856.000,00$ & $\$ 0,00$ & $-100,00 \%$ \\
\hline \multirow[t]{4}{*}{$\begin{array}{l}\text { Cost of off-site services and } \\
\text { infrastructure }\end{array}$} & GL & & & $\$ 0,00$ & $\$ 0,00$ & $\mathrm{~N} / \mathrm{A}$ \\
\hline & & & & $\$ 0,00$ & $\$ 0,00$ & $\mathrm{~N} / \mathrm{A}$ \\
\hline & & & & $\$ 0,00$ & $\$ 0,00$ & $\mathrm{~N} / \mathrm{A}$ \\
\hline & & & & $\$ 0,00$ & $\$ 0,00$ & N/A \\
\hline Financial costs** & $\%$ & $4,00 \%$ & & $\$ 0,00$ & $\$ 981.450,00$ & N/A \\
\hline Profits ${ }^{* * *}$ & GL & $7,62 \%$ & $\$ 148.120 .454,00$ & $\$ 11.286 .778,59$ & $\$ 11.288 .209,00$ & $0,01 \%$ \\
\hline Costs of building the project ${ }^{\star \star \star \star / \star \star \star \star \star *}$ & GL & & & $\$ 0,00$ & $\$ 94.001 .512,00$ & N/A \\
\hline Indirect Costs of building the project $t^{\star \star \star \star}$ & GL & & & $\$ 0,00$ & $\$ 25.785 .552,00$ & N/A \\
\hline Pre-development Costs ${ }^{\star \star \star *}$ & GL & & & $\$ 0,00$ & $\$ 900.000,00$ & N/A \\
\hline Benefits & & & & $\$ 117.846 .724,43$ & $\$ 148.120 .454,00$ & \\
\hline Subsidies from the government & GL & 0,00 & $\$ 0,00$ & $\$ 0,00$ & $\$ 0,00$ & N/A \\
\hline Development rights received & GL & & & $\$ 117.846 .724,43$ & $\$ 148.120 .454,00$ & $25,69 \%$ \\
\hline Commerce & M2 & $10.557,00$ & $\$ 851,09$ & $\$ 8.985 .000,00$ & $\$ 0,00$ & $-100,00 \%$ \\
\hline \multirow[t]{2}{*}{ Housing } & M2 & $97.539,00$ & $\$ 1.116,08$ & $\$ 108.861 .724,43$ & $\$ 0,00$ & $-100,00 \%$ \\
\hline & & & & & $\$ 0,00$ & $\mathrm{~N} / \mathrm{A}$ \\
\hline
\end{tabular}

\section{e. Summary Sheet}

\begin{tabular}{|l|c|r|}
\hline \multicolumn{1}{|c|}{ Item } & Unit & UAU-5 \\
\hline Participation & & $100,00 \%$ \\
\hline $\begin{array}{l}\text { percentage of landowners participating } \\
\text { Percentage of Local Government owned }\end{array}$ & $\%$ & \\
land & $\%$ & $5,00 \%$ \\
\hline
\end{tabular}




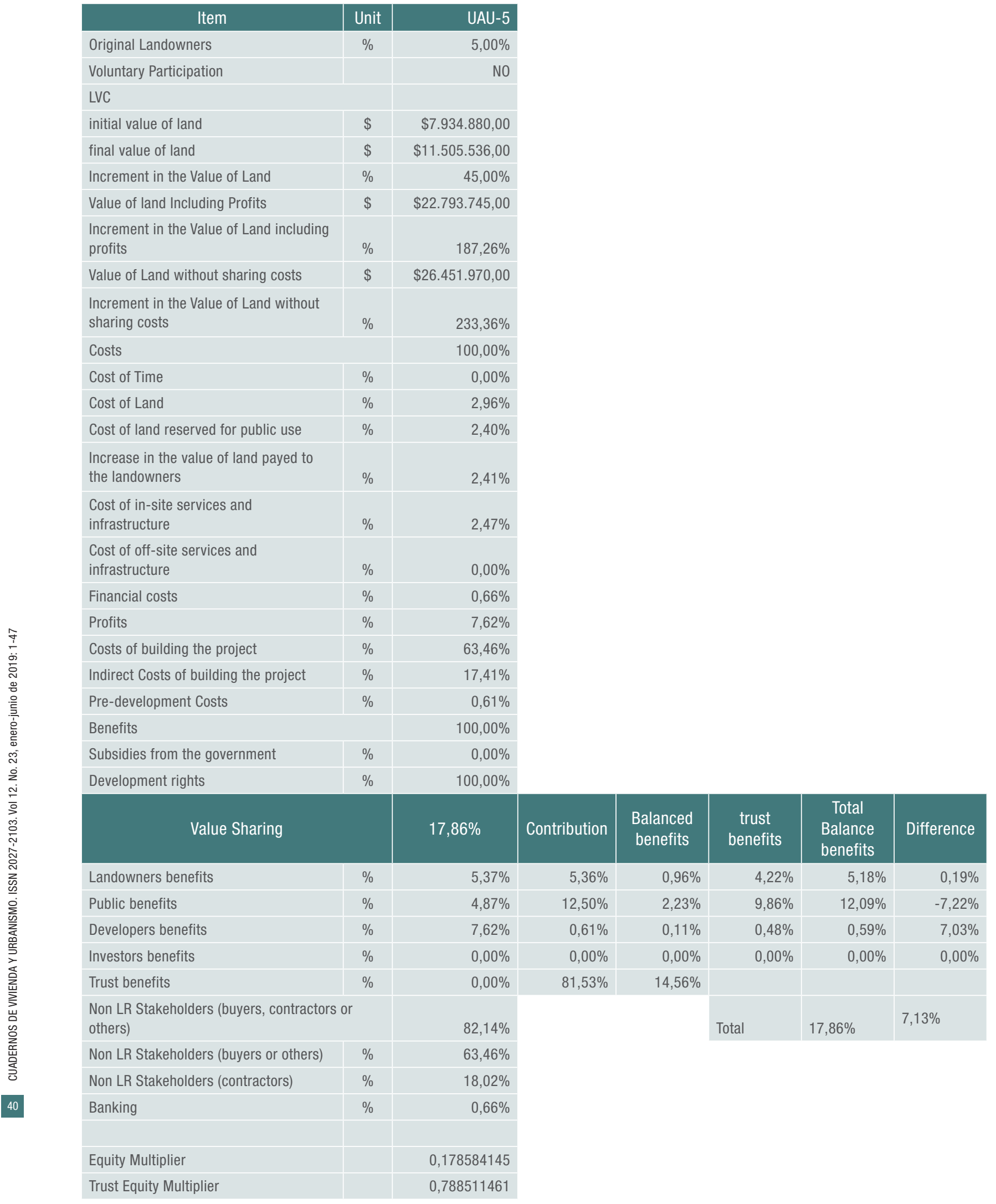




\section{Anexo 4. Interview Manual}

Are the stakeholders of enacted Land Readjustment (LR) projects in Colombia Sharing the Value of Land equitably?

\section{Personal Introduction}

The objective of this research is to document the process of implementation of Land Readjustment projects in Colombia and its effect in the equitable distribution of costs and benefits.

The questions are oriented to understand in dept how the project was conceived and to clarify specific aspects about the decree and the Technical Support Document - DTS.

This interview will take approximately 45 minutes, I will like to ask you if it is okay to record the interview since the transcripts of the interview will be more reliable for the research evaluation and it will allow for a better development of the interview.

The information collected during this interviews is purely academic and completely confidential, the recordings will not be release in any media.

\section{Stakeholders}

, Can you explain how was your participation in the project?

, Did the landowners participated in the decision-making process?

- How?

- What is the decision-making process like?

, Was the project explained in details to the landowners?

- How many meetings were hold with landowners?

- What kind of decisions were taken by the landowners?
Where there reluctant landowners?

- Was the process delayed because of land ownership disputes?

> Did the government had to acquire land?

- How?

- ALTERNATIVE: can you explain how was the expropriation (or compulsory purchase) process in this project?

, Is there any measure for landowners to remain after the project?

, Is there any measure to reduce or prevent plot speculation?

> Is there any solution for landowners who want to leave the project?

\section{Cost and Benefits}

Did the project calculated the initial and final value of land?

- How

- ALTERNATIVE: why it is not stated in the Technical Support Document DTS?

, What type of costs were included?

- Is the cost of time included?

- Is the cost of land included?

- CONDITIONAL: Also the expropriated or purchased land?

- Is the cost of land reserved for public use included?

- Is the cost of on-site services and infrastructure included?

- Is the cost of off-site services and infrastructure included?

- Are financial costs included? 
- Are profits included as costs?

- Are the costs of building the project included?

, Which where the benefits received by the stakeholders?

- Is the project receiving subsidies from the government?

- Is the project receiving extra development rights from the government?

- How many?

- Are the landowners receiving serviced land, development rights or payment at the end of the process?

- How are the landowners getting all the benefits they are entitled to?

- Are they selling land or rights to cover the development of the infrastructure and services?

- Are they selling land or rights to cover the development of the project?

\section{Sharing the Value}

- Is the value being mobilized or paid out by some stakeholders?

- How was the increase of the value of land being distributed amongst stakeholders?

1 Is there any assessment process for equality of landowners?

- How is the sharing of the costs and the profits?

Están los actores de los proyectos de reajuste de tierras promulgados compartiendo equitativamente el valor de la tierra?

Mi nombre es Ricardo Daza, estoy desarrollando mis estudios de maestría en Holanda en la Universidad de Erasmus - IHS dentro de la especialización dirigida por Carlos Morales en Land Value Capture. Mi tesis analiza los proyectos de reajuste de tierras en Colombia a través de los decretos de los Planes Parciales aprobados para medir el impacto que tiene la participación de los propietarios en la distribución equitativa de cargas y beneficios.

El Objetivo de este estudio es documentar el proceso de implementación de los proyectos de Reajuste de tierras/integración inmobiliaria (LR) desarrollados en Colombia y su efecto en la distribución equitativa de costos y beneficios.

Las preguntas están orientadas a entender a profundidad como fue concebido el proyecto y clarificar aspectos específicos acerca del decreto y el Documento Técnico de Soporte - DTS.

La entrevista tomará aproximadamente 45 minutos, para tener una transcripción más confiable de la entrevista, mejorar la calidad de la recolección de información y tener una conversación más fluida, me gustaría solicitar su permiso para grabar la entrevista.

La información recolectada durante la entrevista es de carácter netamente académico y do total confidencialidad, las grabaciones no serán compartidas en ningún medio de comunicación o difusión.

\section{Acerca de los actores}

- Por favor explique cómo fue su participación en el proyecto.

- ¿Participaron los propietarios en el proceso de toma de decisiones?

- ¿Cómo participaron?

- ¿Cómo es el proceso de toma de decisiones?

- Se explicó en detalle el proyecto a los propietarios? 
- ¿Cuántas reuniones se hicieron con los propietarios?

- ¿Qué tipo de decisiones fueron tomadas por los propietarios?

' ¿Hubo propietarios renuentes?

- ¿Se demoró el proceso por disputas de los propietarios?

¿El Gobierno ha tenido que adquirir propiedades?

- ¿Cómo?

- ALTERNATIVA: ¿puede usted explicar cómo fue el proceso de expropiación/venta en este proyecto?

, ¿Existe alguna medida para que los propietarios permanezcan después del proyecto?

, ¿Existe alguna medida para reducir o prevenir la especulación inmobiliaria?

> ¿Hay alguna solución para los propietarios que quieren abandonar el proyecto?

\section{Costos y beneficios}

, ¿El proyecto calcula el valor inicial y final de la tierra?

- ¿Cómo?

- ALTERNATIVA: ¿Por qué el valor de la tierra no está indicado en el DTS?

¿Qué tipo de costos fueron incluidos?

- ¿Está el costo del tiempo incluido?

- ¿Está el costo de la tierra incluido?

- CONDITIONAL: ¿también el de los terrenos expropiados o adquiridos?

- ¿Está el costo de la tierra reservada para usos públicos incluida?

- ¿Están el costo de la infraestructura y los servicios al interior del proyecto ¿incluidos?

- ¿Está el costo de la infraestructura y los servicios al exterior del proyecto incluido?

- ¿Están incluidos los costos financieros?

- ¿Están las utilidades incluidas como costos?

- ¿Están los costos de construcción de las edificaciones incluidos?

¿Cuáles son los beneficios recibidos por los actores (propietarios u otros)?

- ¿El proyecto recibe subsidios del Gobierno?

- ¿El proyecto recibe derechos de desarrollo (edificabilidad) adicionales del Gobierno?

- ¿Cuántos?

- ¿Los propietarios reciben propiedades, derechos o dinero al final del proceso?

- ¿Cómo están los propietarios recibiendo todos los beneficios que les corresponden?

- ¿Están vendiendo tierra o derechos para cubrir el desarrollo de la infraestructura y los servicios?

- ¿Están vendiendo tierra o derechos para cubrir el desarrollo del proyecto?

\section{Compartiendo el valor}

> ¿Las plusvalías son pagadas o movilizadas al interior del proyecto?

> ¿Cómo se distribuye el incremento en el valor de la tierra entre los diferentes actores?

, ¿Existe algún proceso de evaluación del reparto equitativo entre propietarios?

- ¿Cómo es el balance entre los costos y las utilidades? 


\section{Anexo 5. Sample Distribution}

\begin{tabular}{|c|c|c|c|c|c|c|c|c|c|c|c|c|c|}
\hline \multicolumn{8}{|c|}{ Partial Plans by city } & \multicolumn{3}{|c|}{$\begin{array}{l}\text { Development } \\
\text { (Desarrollo) }\end{array}$} & \multicolumn{3}{|c|}{$\begin{array}{c}\text { Redevelopment } \\
\text { (Renovación Urbana) }\end{array}$} \\
\hline City & enacted & $\%$ & \multicolumn{2}{|c|}{ Sample } & \multicolumn{3}{|c|}{ Regional distribution } & \# & $\%$ & Sample & \# & $\%$ & Sample \\
\hline Medellín & 32 & $17,78 \%$ & 5,33 & 5 & 7,17 & 7,00 & 5,00 & & & 2 & & & 2 \\
\hline Apartadó & 1 & $0,56 \%$ & 0,17 & 0 & & & & & & & & & \\
\hline Bello & 1 & $0,56 \%$ & 0,17 & 0 & & & & & & & & & \\
\hline Envigado & 9 & $5,00 \%$ & 1,50 & 2 & & & 2,00 & & & 1 & & & 1 \\
\hline Itagüí & 0 & $0,00 \%$ & 0,00 & 0 & & & & & & & & & \\
\hline Barranquilla & 3 & $1,67 \%$ & 0,50 & 1 & 1,00 & 1,00 & 1,00 & & & 1 & & & \\
\hline Soledad & 0 & $0,00 \%$ & 0,00 & 0 & & & & & & & & & \\
\hline Bogotá, D.C. & 45 & $25,00 \%$ & 7,50 & 8 & 7,67 & 8,00 & 8,00 & & & 5 & & & 2 \\
\hline Chia & 1 & $0,56 \%$ & 0,17 & 0 & & & & & & & & & \\
\hline Cartagena & 0 & $0,00 \%$ & 0,00 & 0 & & & & & & & & & \\
\hline Tunja & 0 & $0,00 \%$ & 0,00 & 0 & & & & & & & & & \\
\hline Manizales & 0 & $0,00 \%$ & 0,00 & 0 & & & & & & & & & \\
\hline Florencia & 0 & $0,00 \%$ & 0,00 & 0 & & & & & & & & & \\
\hline Popayán & 5 & $2,78 \%$ & 0,83 & 1 & 1,17 & 1,00 & 1,00 & & & 1 & & & \\
\hline Valledupar & 1 & $0,56 \%$ & 0,17 & 0 & & & & & & & & & \\
\hline Montería & 1 & $0,56 \%$ & 0,17 & 0 & & & & & & & & & \\
\hline Soacha & 0 & $0,00 \%$ & 0,00 & 0 & & & & & & & & & \\
\hline Quibdó & 0 & $0,00 \%$ & 0,00 & 0 & & & & & & & & & \\
\hline Neiva & 0 & $0,00 \%$ & 0,00 & 0 & & & & & & & & & \\
\hline Riohacha & 0 & $0,00 \%$ & 0,00 & 0 & & & & & & & & & \\
\hline Santa Marta & 1 & $0,56 \%$ & 0,17 & 0 & & & & & & & & & \\
\hline Villavicencio & 6 & $3,33 \%$ & 1,00 & 1 & 1,00 & 1,00 & 1,00 & & & 1 & & & \\
\hline Pasto & 2 & $1,11 \%$ & 0,33 & 0 & & & & & & & & & \\
\hline Cúcuta & 3 & $1,67 \%$ & 0,50 & 1 & & & 1,00 & & & 1 & & & \\
\hline Armenia & 1 & $0,56 \%$ & 0,17 & 0 & & & & & & & & & \\
\hline Pereira & 27 & $15,00 \%$ & 4,50 & 5 & 5,33 & 5,00 & 4,00 & & & 2 & & & 2 \\
\hline Dosquebradas & 4 & $2,22 \%$ & 0,67 & 1 & & & 1,00 & & & 1 & & & \\
\hline Bucaramanga & 0 & $0,00 \%$ & 0,00 & 0 & & & & & & & & & \\
\hline Barrancabermeja & 0 & $0,00 \%$ & 0,00 & 0 & & & & & & & & & \\
\hline Floridablanca & 5 & $2,78 \%$ & 0,83 & 1 & 1,33 & 1,00 & 1,00 & & & 1 & & & \\
\hline Girón & 0 & $0,00 \%$ & 0,00 & 0 & & & & & & & & & \\
\hline Sincelejo & 0 & $0,00 \%$ & 0,00 & 0 & & & & & & & & & \\
\hline Ibagué & 9 & $5,00 \%$ & 1,50 & 2 & 1,50 & 1,00 & 1,00 & & & 1 & & & \\
\hline Cali & 20 & $11,11 \%$ & 3,33 & 3 & 3,67 & 4,00 & 3,00 & & & 1 & & & 1 \\
\hline Buenaventura & 0 & $0,00 \%$ & 0,00 & 0 & & & & & & & & & \\
\hline Cartago & 0 & $0,00 \%$ & 0,00 & 0 & & & & & & & & & \\
\hline
\end{tabular}




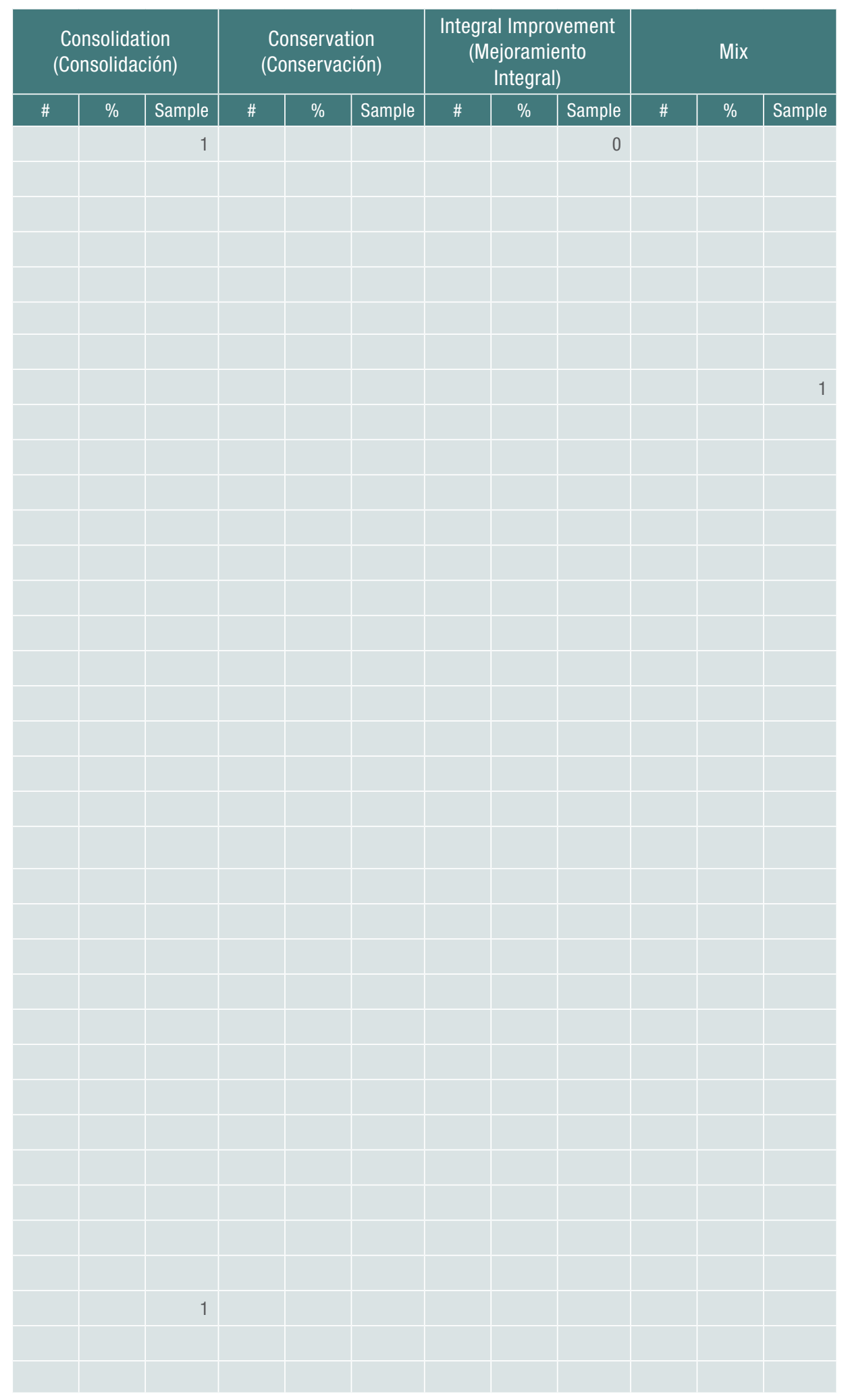




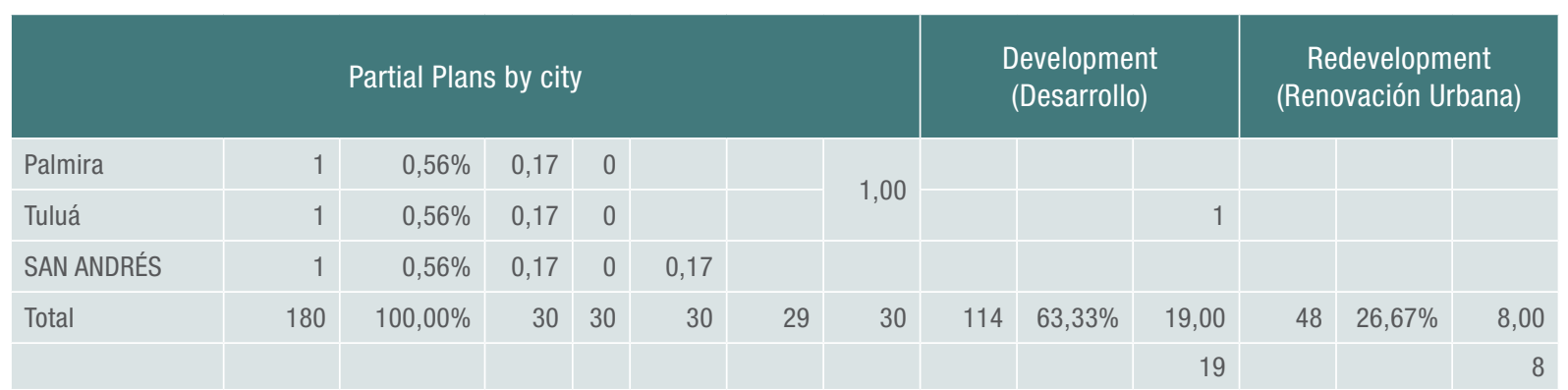

* La información del área registrada no corresponde al $100 \%$ de los datos disponibles que han sido reportados por las ET (Ios Municipios de Bello y pasto no reportaron datos de Área en PP de RU; Bogotá no reporta el área de 22 PP de los cuales 4 están en tratamiento de RU, Barrancabermeja no reporta el área de 2 PP en RU; Cali no reporta el área de PP en RU

** El municipio de Bello no reporta información adicional al nombre de los PP

*** Los municipios de Pasto y Valledupar no reportan área de PP en tratamiento de Desarrollo, Ibagué no reporta área de 4 PP de los cuales 1 esta en tratamiento de Desarrollo

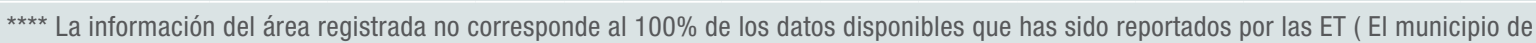
Valledupar no reporta el área del PP en tratamiento de MIB, Cali no reporta el área de 1 PP en MIB

***** La información del área del PP de Desarrollo y Mejoramiento no se encuentra disponible, y Cali no tiene información disponible de 1 de PP mixtos 


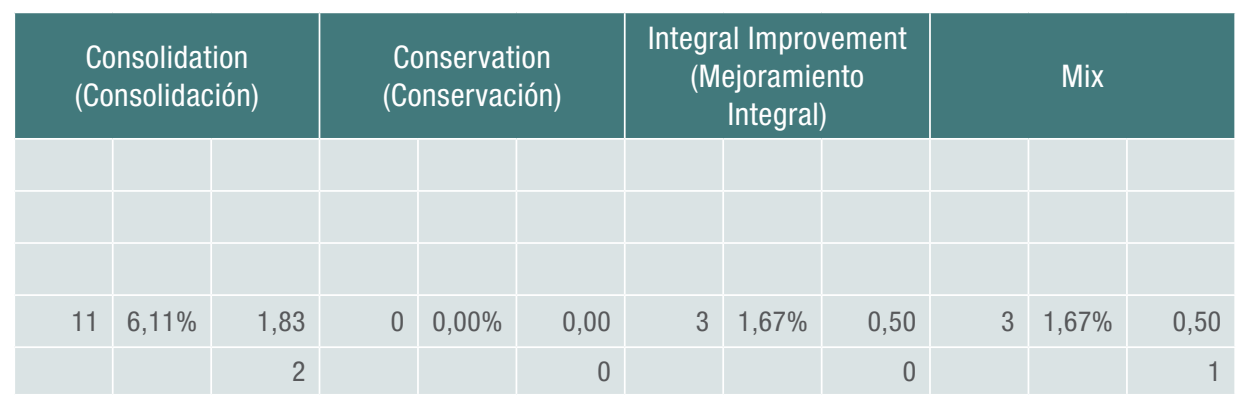

